\title{
EFEITO DE ÉPOCAS DE PLANTIO, PESOS DE MUDAS E ESPAÇAMENTOS SOBRE O PESO DOS FRUTOS DE ABACAXI (Ananas comosus (L.) Merr.), CULTIVAR "SMOOTH CAYENNE", NA ZONA DA MATA DO ESTADO DE MINAS GERAIS
}

José Maurício Fortes

Orientador: SALIM SIMÃO

Tese Apresentada à Escola Superior de Agricultura «Luiz de Queiroz», da Universidade de São Paulo, para Obtenção do Título de Doutor em Agronomia, na Área de Solos e Nutrição de Plantas.

$\mathbb{P I} \mathbb{A} \mathbb{C} \mathbb{C} A \mathbb{B}$

Estado de São Paulo - Brasil

Mraio de 1981 
A Deus.

I. memória de meu paig Francisco.

A minha mãe, Antonina.

Aos Pobres e Marginalizados.

A meus filhos

Junior, Iuciane, Cristiane e Cristiano. 
AGRADECIIENTOS

A Universidade Federal de Viçosa, à Escola Superị or de Agricultura "Luiz de Queiroz" e ao Conse Iho Nacional de Desenvolvimento Científico e Tecnológico, que tornaram possí vel a participação no curso de PósmGraduação.

Ao Professor Salim Simão, pela orientação.

Aos Professores Braz Vítor Defelipo e Geraldo Iuiz Pinto, pelas análises follares e dos frutos.

Ao Professor e amigo Iaede liaffia de Oliveira, que colaborou nas análises estatísticas, interpretação e reda ção dos resultados estatísticos.

Ao Professor Renato Ilário del Giudice, colega de curso e amigo, pelo apoio e compreensão, de um verdadeiro pai, nos moinentos mais difíceis derminha vida.

Aos Professores Salim Simão, Heitor W. S. Pintere. gro, ilenrique Paulo Haag, Hoacir de Oliveira C. do Brasil So brinho, Francisco de Aśsis Ferraz de Melo, Guido Ranzani, Sil vio Arzolla e Geraldo V. França.

Aos Senhores Antōnio Iisboa de Silva e Wagner Bar bosa, pela grande ajuda durante o desenvolvinento do trabalho de campo.

Ao Iuís Carlos Veríssimo, pela ajuda na Bibliote ca Central.

A todos aqueles que, direta ou indiretamente, aj.l daram a concluir o curso de Doutorado. 


\section{INDICE}

Página

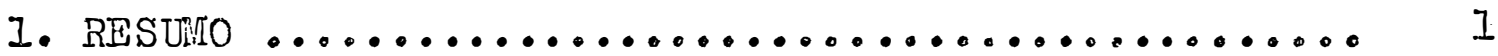

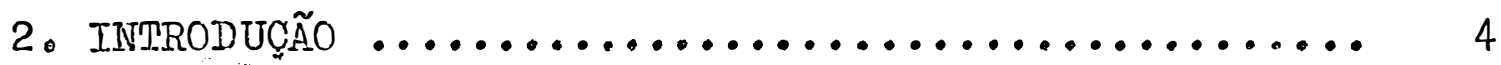

3. IEVISÃO DE IITERATURA $\ldots \ldots \ldots \ldots \ldots \ldots \ldots \ldots \ldots$

3.1. Efeito de épocas de plantio sobre o peso mé dio dos frutos ...................... 6

3.2. Efeito de épocas de colheita no brix, na aci dez total e na relação brix/acidez dos frutos II

3.3. Ffeito de espaçamentos sobre o peso médio dos

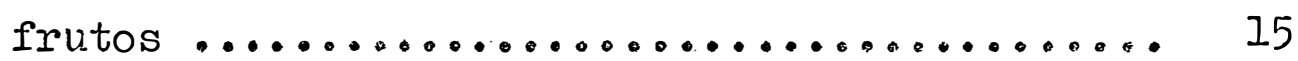

3.4. Efeito dos diferentes pesos de mudas sobre o peso médio dos fruto:.................. 23

3. i. Efeito dos teores de riatrientes da folha "D" sobre o peso médio dos frutos ........... 30

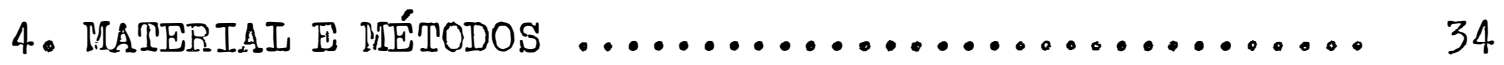

4... Loca Iização do experimento ............. 34

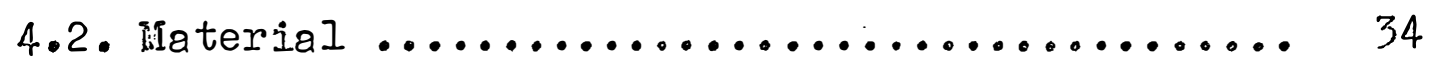

4.2.1. Características do clina e do solo ... 34

4.2.2. Planta ......................... 36

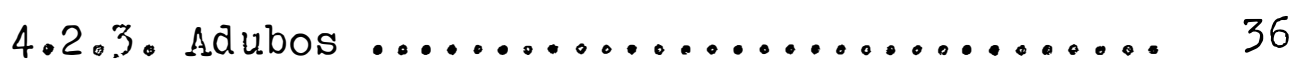

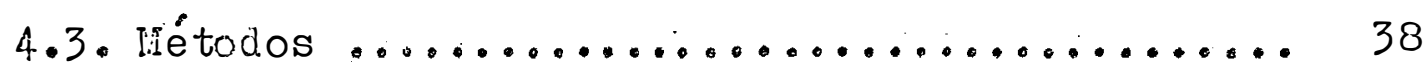

4.3.2. Delineamento experimental ......... 38

4.3.2. Instalação e condução do experimento.. 39 
Pázina

4.3.3. Avaliações ..................... 40

4.3.4. Análises Estatísticas .............. 42

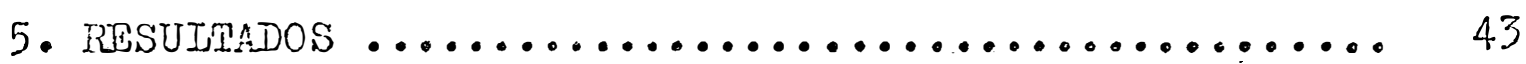

5.1. Brix médio dos frutos ................. 43

5.2. Acidez média titulável dos frutos .......... 45

5.3. Relação média brix/acidez dos frutos ....... 47

5.4. Efeito de espaçamentos sobre o peso médio dos

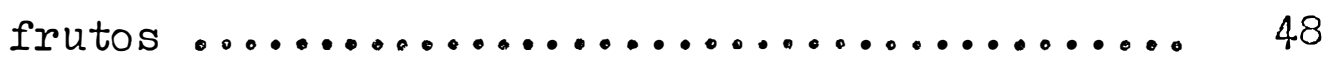

5.5. Efeito de diferentes pesos de mudas sobre o pe so médio dos frutos .................... 49

5.5.1. Plantio da época chuvosa ............ 49

5.5.2. Plantio da época seca ............. 50

5.6. Ifeito de diferentes pesos de mudas, plantadas na época seca, e diferentes teores de nutrien tes da folha "D" sobre o peso médio dos frutos 52

5.6.1. Efeito de diferenties pasos de mudas e diferentes teores de $N, P$ e $K \ldots \ldots . . .52$

5.6.2. Ifeito de diferentes pesos de mudas e diferentes teores de Ca ............ 54

5.6.3. Efeito de diferentes pesos de mudas e diferentes teores de $\mathrm{Mg}$............ 55

5.6.4. Efeito de diferentes pesos de mudas e diferentes teores de $s \ldots . . . \ldots \ldots . . .59$

5.7. Ifeito de diferentes pesos de mudas e épocas de plantio sobre o peso médio dos frutos ..... 60 
vi。

Página

6.1. Brix médio dos frutos .................. 64.

6.2. Acider média titulável dos frutos ........... 66

6.3. Relação média brirr/acidez dos frutos ....... 67

6.4 . Efeito de espaçamentos sobre o peso médio dos

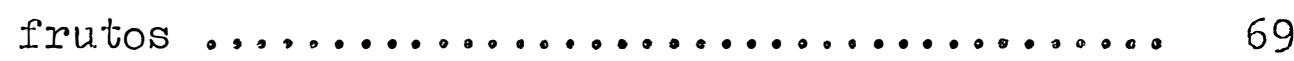

6.5. Preito de diferentes pesos de mudas sobre o peso médio dos frutos ...................... 7 I

i.6. Ereito dos teores de nutrientes da follia "ID" sobre o peso médio dos frutos ............. 72 6.6.1. Ifeito dos teores de $N, P$ e $K \ldots . . . . .72$ 6.6.2. Ifeito dos teores de Ca, IIf e S ..... 74

6.7. Efeito de épocas de plantio (churosa e seca) sobre o peso médio dos frutos ........... 75

7. COICIUSOTS .............................. . 77

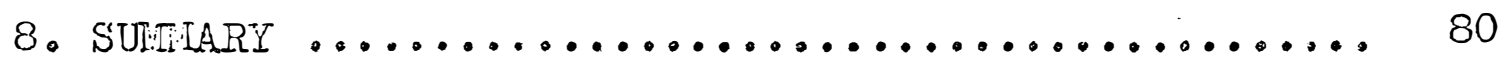

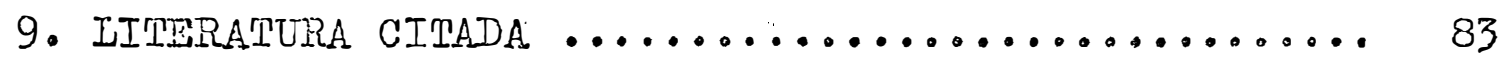

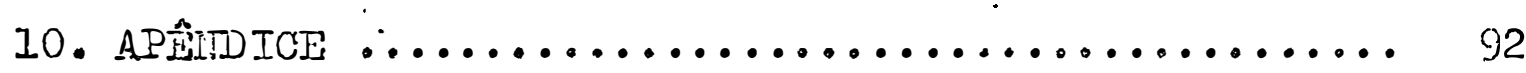


IISTA DE IABEIAS

Tabela

Página

1. Médias mensais, de novembro de 1972 a janeiro de 1975, das características climáticas da re gião

2. Resultados das análises físicas e químicas de amostras do solo, a 0,20 m de profundjdade, do local onde foi instalado o ensaio

3. Análise de variância dos dados relativos ao efeito de épocas de colneita sobre o brix dos frutos ..........................

4. Lifeito de épocas de colheita sobre o brix mé

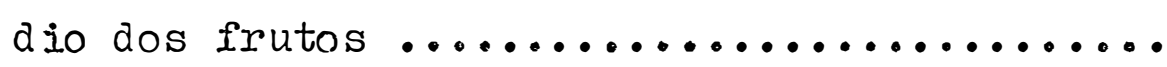

5. Análise de varianncia dos dados relativos ao efeito de épocas de colheita șobre a acidez titulável dos frutos ...................

6. Efeito de épocas de colheita sobre a acj.der média titulável dos firutos ................. efeito à épocas de colhej.ta sobre a relação

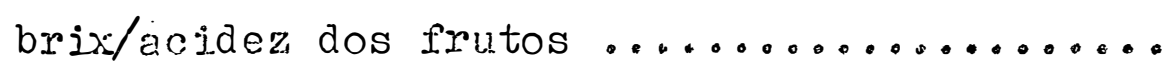


Tabela

8. Efeito de épocas de colheita sobre a relação média brix/acidez dos frutos

9. Coeficjentes de regressão estimados $\left(\hat{b}_{j}\right)$, des vios-padrão desses coeficientes $s\left(b_{i}\right)$, valo res de t, de "Student", e coeficientes de de terminação $\left(r^{2}\right.$ e $\left.\bar{r}^{2}\right)$, para pesos de frutos de abacaxizeiro, em função de diferentes pesos de mudas, plantadas na época chuvosa .......

10. Coeficientes de regressão estimados $\left(\hat{b}_{j}\right)$, des vios-padrão desses coeficientes $s\left(b_{i}\right)$, vale res de $t$, de "Student", e coefientes de de terminação $\left(r^{2}\right.$ e $\left.\bar{r}^{2}\right)$, para pesos de frutos de abacaxizeiro, em função de diferentes pesos de mudas, plantadas na época seca .........

11. Coeficientes de regressão estimados $\left(\hat{b}_{i}\right)$, des vios-padrão desses coeficientes $\mathrm{s}\left(\hat{b}_{i}\right)$, valo res de t, de "Student", e coeficientes de de terminação $\left(R^{2}\right.$ e $\left.\overrightarrow{\mathrm{R}}^{2}\right)$, para pesos de frutos de abacaxizeiro, em Iunção de diferentes pesos de mudas, plantadas na época seca, e diferen tes teores de Ca na folha "J" ...........

22. Coeficientes de recressão estinacios $\left(\hat{b}_{i}\right)$, dess viosmpadrão desses coeficientes $s\left(\hat{b}_{j}\right)$, valo res de $t$, de "śtudent", e coeficientes de de 
terminação $\left(\mathbb{R}^{2}\right.$ e $\widetilde{R}^{2}$ ), para pesos de frutos ae abacaxizeiro, em função de diferentes pesos de mudas, plantadas na época seca, e diferentes teores de $M g$ na folha $" D " . . . . . . . . . . . .$.

13. Coeficientes de regressão estimados $\left(\hat{b}_{i}\right)$, desvios-padrão desses coeficientes $s\left(\hat{b}_{i}\right)$, valores de t, de "Student", e coeficientes de determinação $\left(R^{2}\right.$ e $\left.\tilde{R}^{2}\right)$, para pesos de frutos de abaca xizeiro, em função de diferentes pesos de mu das, plantadas na época seca, e diferentes, te

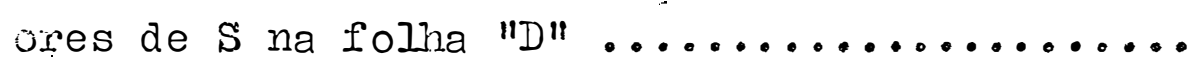

14. Coeficientes de regressäo estinados, coeficien tes de determinação $\mathrm{R}^{2}$ para equações a.lternati vas e análise de variância da resressão dos dados de pesos médios de frutos do abacaxizeiro, em função de pesos de nudas e épocas chuvo sa e seca $\ldots \ldots \ldots \ldots \ldots \ldots \ldots \ldots \ldots \ldots \ldots$

15. Resultados médios de pesos de frutos, em fun ção de espaçamentos e pesos de mudas, no plan tio de época chuvosa ..................

16. IResultados médios de pesos de frutos; en lun ção de espaçanentos, pesos de nudias c teores de II, $\mathrm{P}, \mathrm{K}, \mathrm{Ca}$, i. $\mathrm{Ig}$ e $\mathrm{S}$, no plantio da é,ooca seca.. 
IISTA DE FTGURAS

Pigura

1. Pesos de frutos de abacaxizeiro $\left(\hat{Y}_{i}\right)$, em fun ção de diferentes pesos de mudas $\left(X_{i}\right)$, planta

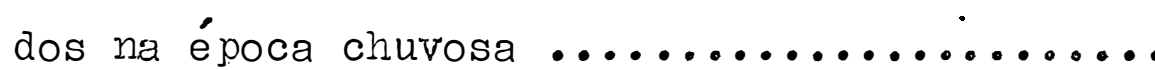

2. Pesos de frutos de abacaxizeiro $\left(\hat{Y}_{i}\right)$, em fun ção de diferentes pesos de múdas $\left(\mathrm{X}_{i}\right)$, planta dos na época seca

3. Pesos de frutos de abacaxizeiro $\left(\hat{Y}_{\hat{i}}\right)$, em fun s̃̃o de diferentes pesos de mudas $\left(X_{i}\right)$, planta dos na época seca, e do teor de Ca da folha :

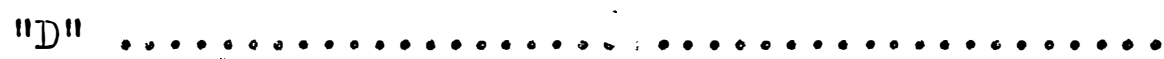

4. Pesos de frutos de abacaxizeiro $\left(\hat{Y}_{i}\right)$, em fun ção de diferentes pesos de mudas $\left(x_{i}\right)$, planta dos na época seca, e do teor de lifg da folha. $" 1 " \ldots \ldots \ldots \ldots \ldots \ldots \ldots \ldots \ldots \ldots \ldots \ldots \ldots \ldots \ldots \ldots$

5. Pesos de frutos de abacaxizeiro $\left(\hat{Y}_{i}\right)$, em fun ção de diferentes pesos de mudas $\left(X_{j}\right)$, plante dos na época seca, e do teor de $S$ da folha"D" 
6. Pesos de frutos de abacaxizeiro $\left(\hat{Y}_{i}^{C}\right.$ e $\left.\hat{Y}_{i}^{S}\right)$, em função de diferentes pesos de mudas $\left(K_{i}\right), p l a n$ tados nas épocas chuvosa e seca .......... 
1. RESUIO

Este trabalho foi conduzido em área da Estação Ex perimental de Visconde do Rio Branco, Minas Gerais, na Zona da liata ilineira, que tem condições climáticas muito favoráveis ao cultivo do abacaxizeiro.

o objetivo foi determinar o comportamento da cul tura d'o abacixi. "Smooth Cayenne" Ananas comosus (I0) Herr, nes sa região, verificando-se o efeito de épocas de plantio (chum vosa e seca), espaçamentos, diferentes pesos de nudas e teores de nutrientes das folhas "D" sobre o peso médio dos fru tos. Determinou-se, também, o efeito de épocas de colheita so bre brix médio, acidez média e relação brix/acidez dos frutos colnidos.

Os tratamentos foram dispostos em parcela subdivi didas, no delineamento em blocos casualizados, com 7 repeti cões e 1.2 plantas úteis por subparcelas. As plantas foram dispostas em filleiras duplas, sendo os tratamentos circunda dos por bordadura. Decorxidos doze meses do plantio da épocá 
seca, foi fieita a coleta das folnas "D" e determinados os teo res de H, P, K, Ca, $\mathrm{Hg}$ e $\mathrm{S}$.

A colheita dos frutos plantados na época chuvosa (20/11/72) Loi feita de junho a agosto de 1974; a do plantio da época seca (20/04/73), de dezembro de 1974 a reverejro de 1975. Foram determinados os pesos médios dos frutos e ieitas as análises do suco para brix, acidez e relação média brix/ acidez.

Nas condições do trabalino, os frutos colnidos no verăo, plantados na época seca, para o mercaảo externo e a in dústria, apresentaram brix do suco satisfatório, acidez baixa e relação brix/acidez elevada. Eara o consumo ao natural, no mercado interno, os frutos apresentaram bom paladar. Os fru tos colhides no inverno, plantados na época chuvosa, yara o mercacic exterio e a indústria. i.presentaram brix do slco abai xo do satisfatório, acidez elevada e relação brix/acidez bai xa. 0,s frutos eram ácidos para o consumo interno.

Im nenhuma das duas épocas de plantios os espaça. mentos influenciaram significativamente $(P<0,10)$ os pesos mé dios dos frutos. Os pesos de mudas influenciaram significativamente $(P<0,01$ e 0,05$)$ a amento dos pesos médios dos frum tos, em razão do crescente aumento dos pesos das muaas planta das.

Os teores de $N, P$ e $K$ da folha "D" não influencia ram significativamente $(P<0,10)$ e peso nédio dos frutos, que, entretanto, sofreram o efelto significativo dos teores de Ca e $\operatorname{Mg}(P<0,10)$ e $S(P<0,05)$. 
Além da influência significativa $(P<0,01)$ dos pesos das mudas sobre os pesos dos frutos colhidos, verificon se também a influëncia $(P<O, O I)$ das épocas de plantio (seca e chuvosa). 
2. TITTRODUÇÃO

De acordo com o Anuário da Produção, da F'AO (1980), - Brasil ocupa o segundo Iugar como produtor mundial de abacg xi. com uma produção de 572000 toneladas, superad a penas pe Io Havaí, EUA. Minas Gerais fol o segundo Estado de mator pro dução, com 69634 frutas produzidas numa área de 5286 ha. conforine dados do Anuário Futatístico do Brasil (1979).

Enquanto uma parte dos abacaxis produzidos :10 Bra sil é comercializada "in natura", no mercado interno e extes no, outra parte é utilizada como matéria-prima na elaboração de diversos produtos industrializados, principalmente en forma de rodelas, havendo também outzos produtos, como o suco, a geléia, etc。

Tem havido decréscino na exportação de abacaxinos últinos anos, em razão de ser a maior parte da produção bras leira constituída da variedade 'Pérola', cujo fruto é muito doce e pouco ácido, o que não agrada so consumidor europeu, 
e, também, de formato cônico, indesejável para a indústria. Em Minas Gerais, as principais regiões produtoras de abacaxi são a zona hetalúrgica e a do Triangulo, onde se cultiva, principalmente, a variedade 'Pernambuco ilassa Amare la', segundo CARDINALI: (1969).

o cultivar mais plantado no mundo é o 'Smooth Cayenne', que apresenta características desejáveis tanto para a ináústria como para o consumo ao natural.

A Zona da Mata Mineira apresenta regiões com con dições clináticas satisfatórias parà a produção de frutos da variedade 'Smooth Cayenne' para consumo ao natural, exporta ção e industrialização.

Os objetivos deste trabajho foram os seguintes:

a) verificar o efeito de épocas de plantio, espaçamentos, di forentes pesos de mudase teores de nutrientes da folha "D" sobre o peso médio dos fru'ios;

b) estudar o efeito de épocas de colneita sobre brix médio, aciłez média e relação brix/acidez dos frutos. 
3. REVISÃO DE IITERATURA

3.1. Efejto de épocas de plantjo sobre o peso médio dos frutos

GOWIitg (1961) concluiu, com base em resultados ex perimentais com a variedade de abacaxi 'Smooth Cayenne', no Havǻ, que a diferenciação floral do abacaxizeiro não $\dot{\theta}$ uma resposta estrita nem ao fotoperíodo nem à temperatura noturra, mas to zria sofrer a influência do tipo de muda usado e da é. poca to plantio, não importando a época do ano.

PY (1964), estudando o comportamento da variedade 'Smooth Cayeme' em Basse Pointe (Liartinica), utilizando dife rentes pesos de inudas no plantio, chegou às seguintes conclu sões :

a) o abacaxizeiro é planta de dias curtos; porém, além do comprimento das noites, outros fatores do mejo, ainda não determinados com precisão, podem originar a ảferenciação dà inflorescência;

b) a escolna da data de plantio e o peso da nuda 
a ser utiljzada têm influência considerável sobre o cjclo ve getativo do abacaxizeiro e o peso do fruto na colheita, possi bilitando una frutificação mais uniforme, sem que haja co Theita de frutos prematuros, com baixo peso médio;

c) é muito variável o tempo necessário para o iní cio da fase de diferenciação da infloreșcência no abacaxizeiro, ao passo que varia muito pouco o tempo compreendido entre essa fase e a maturação e colheita dos frutos.

GIACORIELII (1972), estudando o efeito de épocas de plantio sobre emissão natural das inflorescēncias e peso médio dos frutos, sem a coroa, no cultivar 'Smooth Cayenne', obteve os seguintes resultados:

a) as mudas plantadas em época churosa (fins de janeiro de 1970), em fins de janeiro de 1971 já apresentavam um desenvo!vimento vegetativo satisfatório, tanto que, em ju Iho desse anu, o peso médio d:s frutos foi de $1.83 \mathrm{~kg}$ mas em plena entressafra, para as corıdições do planalto paulista. Os frutos produzidos nessa época apresentaram sabor bastante áci do;

b) as muảas plantadas em época seca (fins de abril de 1970), aos 12 meses de idade já apresentavam um desenvolvi mento vegeta úivo satisfatório; apesar disso, a colheita só se verificou a partir de janeiro de 1972 (o ciclo foi aunentado 3 meses em relação ao plantio da época chuvosa), tendo sido de $1,78 \mathrm{krcs}$ o peso médio dos frutos. Os frutos produzidos neg sa época tinham sabor bastante doce e pouco ácido. 
PY (1964) fez as seguintes considerações: em Came ron, na istação Experimental do I.P.A.C., foi estudada a in fluência de quatro datas de plantio (15 de fevereiro, 14 de maio, 13 de agosto e 19 de novembro de 1976) e de diferentes pesos de mudas $(200,350$ e $500 \mathrm{~g})$ sobre o desenvolvimento do abacaxizeiro. Verificou-se que; durante a estação seca, o crescimento das plantas foi muito lento (dezembro, janeiro e fevereiro); em plena estação chuvosa (agosto, setembro), ob servou-se, também, um crescimento lento, não só pelo excesso de chuvas;mas também pela insuficiência de insolação; cresci mento muito rápido foi observado no período chuvoso de abril e maio (insolação adequada). Piudas de 200 g. plantadas em 15 de fevereiro, e de 200, 350 e $500 \mathrm{gg}$. plantadas em 14 de majo, deram frutos, na colheita, com baixo peso médio, 1,20 krg; as de $500 \mathrm{~g}$, plantadas em 19 de novemb:o, produziram fruto:3 muj to giandes, com peso médio de $I, 69 \mathrm{~kg}$. Todos os outrus trata. mentos produzirarn frutos cor peso médio de 1,24 a $1,55 \mathrm{~kg}$, pró ximo dos pesos ideais para expcrtação e consumo ao natural, segundo GAIIILARD (1969)。

Temperaturas baixas ou secas prolongadas normal mente retardam o crescimento e desenvolvimento do fruto. AI tas temperaturas diurnas, sefuidas de baixas temperaturas no turnas, durante as últinas semanas de desenvolvinento do $\mathbf{x} \underline{\underline{u}}$ to, parecem ser as condições ideais. A boa distribuição de chuvas é importante no perfodo de formação do fruto, rnas a falta de unidade dirninuirá seu tamaniso (Eovza Jr., 1972). 
De acordo com o IRFA (1977), a insolação e/ou a temperatura têm papel importante no peso final dos frutos. ITa Costa do lifarfim e na lifartinica, observa-se que, com fraca in solação durante o mês que precede a colheita, os frutos apre sentam pesos médios majs baixos.

Segundo COIIIINS (1968), as condições de anibiente, como umidade, temperatura e altitude, influem significativa mente nos caracteres do cultivar 'Smooth Cayenne', tanto na planta como no fruto. 'Em regiões de baixas temperaturas e umidade e altitude elevadas, os frutos são pequenos, com peso médio abaixo de $1,80 \mathrm{~kg}$. Im condições mais amenas, os frutos são de tamanho médio, sendo mais pesados em áreas mais tropi cais.

Estudando o florescimento natural de abacaxize ros na República de Cote d'Ivaire, TEISSON (1972) concluiu que, Levsa região, onde as temperaturas mínimas variam muito pouco durante o ano, a causa principal da diferenciação flo ral natural em abacaxizeiro parece ser a baixa insolaçãc, ao contrário de outros países mais próximos dos trópicos, onde as baixas temperaturas noturnas são o fator mais inportante. PY (1970), em trabalho: experimentais, na Jamaica, com diferentes tipos e pesos de mucas da variedade 'Smooth Cayenne', de 200 a $300 \mathrm{~g}$, de 400 a $500 \mathrm{~g}$ e de 600 a $800 \mathrm{~g}$, plantadas em diversas épocas do ano, em baixas altitudes, e recebendo tratos e adubações uniformes, chegou às seguintes conclusões: 
a) o comprimento do dia é o fator que mais infilui na indução natural da infllorescência, vindo em seģuida a tem peratura, considerando as épocas de plantioss os diversos tị pos, tamarhos e pesos das mudas;

b) planta de dia curto, preferencialmente, a maj or indução de florescimento do abacaxizeiro se verifica quan do os dias são menores e as temperaturas mais baixas, 0 que está de acordo com trabalhos de VAN OVERBECK e CRURADO (1948) citados por TEISSON (1972), que, trabalhando em Porto Rico, provocaram indução de florescimento na variedade de abacaxi 'Red Spanish';

c) plantios feitos na Tartinica, em janeiro, com di ferentes tipos e tamanhos de mudas, receberam a inaução de florescimento na estação de dias curtos, de dezembro do mesmo ano a fevereiro do ano seguinte, verificando-se o florescimen to de $30 \%$ das plantas, que pæoduziram frutos de tamanho comer cial, 1,30 a $1,80 \mathrm{~kg}$, o que está da acordo com observaçces de HAEITLER e PY (1971), quando se referem às qualidades dcs frü tos da variedade 'Smooth Cayenne'.

d) plantios feitos em abril receberam a indução de florada no mesmo período anterivr, con 45 a $80 \%$ de flores cimento, variação que resultou da diferença de tipos, tama nhos e pesos de mudas.

e) plarstios feitos de julho a ovtubro sofreram in dução no mesmo período (dias curtos de dezembro do mesmo ano a fevereiro do ano sequinte). As mudas, muito grandes e posa 
das, com reservas suificientes, induzidas a florescimento pre maturo, produziram frutos pequenos, sem valor comercial. As mudas nédias e pequenas continuaram seu desenvolvimento vege tativo.

f) dias de verão nublados, chuvosos e com redução de temperatura, em reziões altas, podem provocar um segundo período anual de indução dé florescimento e devem produzir o mesmo efeito dos dias curtos da estação mais fria (responsável pela entressafra que se verifica na Zona da Hata Mineira e ern regiões semelhantes do Brasil).

Algumas dessas conclusões foram obtidas, prelimi narmente, em Guadalupe (Estação do I॰F•A॰C॰), onde PY et aI (1968) estudaram o efeito de diferentes épocas de plantios, tipos e pesos de mudas de variedade 'Snnooth Cayenne'.

Segundo PY (1973), plantios em regiões quentes e úmidas permitem redução de 4 a 6 meses no ciclo da pla:iti, pa rd obtenç̌̃o de frutos com $1.800 \mathrm{~g}$ de peso médio, paira c culti var 'Smooth Cayenne'.

3.2. Ifeito de épocas de colheita no brix, na acidez total e na relacião brix/acidez dos frutos

HAAG et alii (1963), estudando a situação mineral da variedade 'Pérola', obtiveram frutos, na colheita, com $14,7 \%$ de brix médio e 1,.26\% de ácido cítrico (esse percentual corresponde a $90 \%$ da acidez total). 
Estudando a maturação do abacaxi, MON'TREGRO(1964) encontrou, para a variedade 'Pérola', em frutos destinados a mercado próxjmo, brjx de $12,6 \%$, acidez de $0,32 \%$ e relação acj dez $x$ brix de 1: 39.3, em dados médios.

De acordo com DUIJ (1971), com base em trabalho de vários autores, a composição química geral da polpa do fruto maduro do cultivar 'Smooth Cayenne', em percentagem de peso fresco da polpa é a seguinte: brix de 10,8 a $17,5 \%$ e acidez ti tulável de 0,6 a $1,62 \%$ 。

Segundo HAENDIER e PY (1971), o brix (ou teor de sóljdos solúveis) dẹpende essencialmente da insolação e varia relativamente pouco. O brix médio varia de 12,2 a $15,0^{\circ}$, pa ra determinada estação do ano, em Guiné. A acidez total vg ria muito mais e é influenciada essencialnente pela temperatú ra na śpoca da maturação, o que foi confirmado por HUET(1958), tambén um Guiné. É desejáve.l que a acidez corresponda $\varepsilon$ maj.s. de 9 e menos de 15 mililitros de soda 0,1 IN por 10 milizitros de suco.

Estudando a influência da data de plantio sobre o crescimento do abacaxizeiro, e sobre a qualidade dos frutos na colheita, en Cameron, GAILIARD (19009) obteve os serguintes rem sultados:

a) os frutos colhidos em fevereiro, en condições de alta insolação e baixa precipitação, apresentaram, em mé aia, brix de $12,24^{\circ}$, acidez de $7,81 \%$ e relação brix $x$ acidez de 1,66 ; 
b) os frutos colnidos en maio, em condições de alta insolação e precipitação médì, apresentararn, em média s brjx de $13,96^{\circ}$, acidez de 8,79\% $\in$ relação brix / acidez de 1,58;

c) os frutos colhidos em outubro, em condições de insolação média e precipitação alta, apresentaram, em média, brix de $12,54^{\circ}$, acidez de $12,80 \%$ e relação brix / acidez de 0,99;

d) os frutos. colhidos em novembro, em condições de insoläção muito alta e precipitação baixa, apresentaram, em média, brix de $13,11^{\circ}$, acidez de $9,05 \%$ e relação brix/. acidez de 1,53 .

Em estudos realizados no Havaí, COIItIJ (1968)che gou ìs seguintes conclusões:

a) os frutos colnidos em regiões de baixa tempera turas umidade e altitudes elevadas são menores, com baixo contédo de açúcar e acidà éievada.

b) em regiões mais amenas s há aumento do teur de açúcares e é mais baixa a acidez dos frutos.

c) em áreas tropicais, os frutos apresentam alto teor de açúcar e acidez baixa.

Essas conclusões concordam com as de SIITGINTON e GORTIIZR (1965), SGARBIERI (1966), STIÃO (1971), SOUZA J̈ro(1972) e IRFA (1977)。

YTE (I969) obteve, em Johore, estudando diferen tes densidades de plantio, em julho de 1964, com a varjedade 
'Singapore Spanish', colhenōo os frutos de outubro a dezembro de 1965, brix médio de $10,9^{\circ}$ e acidez média de 0,6 (em \% de ácido cítrico).

Em. estudos realizados na China, em que abacaxis. foram plantados no outono e na primavera foram comparados ex perimentalnente, HiNG (1958) obteve brix médio de $12,3^{\circ} \mathrm{e}$ acidez média de 0,53 ( $\%$ de ácido citrico) para os frutos plan tados no outono e brix médio de $11,9^{\circ}$ e acidez média de $0,47 \%$ para os frutos plantados.na prinavera.

De acordo com PY, citado por GIACOMELII (1977), o mercado externo e a indústria preferem frutos menos doces, con brix entre $14^{\circ}$ e $16^{\circ}$, ao passo que o mercado brasileiro dá preferência a frutos mais doces. í desejável que a acidez dos frutos que se destinam à indústria e ao mercado extemo corres ponda a mais de 9 e menos de 15 mililitros de soda $0, I$ iv por. 10 milsilitros de suco, e cue à relaça brix/acidez esteja pró xima e 1,2 .

PY (1973) afirna que, para que o cultivar'Smooth Cayenne' apresente características físicas e organolépticas ó tínas nas últimas fases da maturação do fruto, as conaições devem ser de baixa pluviosidade e insolação relativamenț ele vada e a temperatura média deve ser mantida entre 21 e $23^{\circ} \mathrm{C}$, com diferenças diárias de 12 a $14^{\circ} \mathrm{C}$ 。

GIACOHISLI (.2972), estudando o comportamento do cultivar 'Smooth Cayenne', plantado em 12 de majo de 1970, na resião de Bebedouro, obteve, analísancio os frutos colrijas $\mathrm{cm}$ 
janeiro e fevereiro de 1972, os sęuintes resultados, em mé dia: brix de $16,4^{\circ}$, acidez total de $7,2 \%$ e relação brix/acidez total de 2,3 .

Segundo COSTA (1979), para o mercado interno bra sileiro é desejável que os frutos do cultivar 'Smooth Cayenne' apresentem os seguintes Indices qualitativos: brix de 16,0 a $19,0^{\circ}$, acidez de 7,0 a $12,0 \%$ e relação brix/acidez de 1,3 a 2,7 .

GIACONEIII ett alii (1979), estudando épocas de produção para o abacaxizeiro, cultivar 'Śnooth Cayenne', con cluíram que os valores máximos de brix foram obtidos quando a maturação se deu em época quente e úmida, o que, por sua vez, provocou queda consjiderável da acidez.

3.3. Efejto de espacamentos sobre o peso méd jo dos frutos

YOSH THARA e FIAITG (1957) estudaram diferentas $\in \underline{S}$ paçamentos no cultivo de abacaxizeiros. Entre canteiros (fi leiras duplas) os espaçamentos variaram de 1,00 até 1,2.0m; en tre fileiras, de 0,30 até $0,45 \mathrm{~m}$ e, entre plantas nas filei ras, de 0,45 a $0,60 \mathrm{~m}$. As populariões varjaram de $26930^{\circ}$ a 41660 plantas por hectare e os pesos médios dos frutos colhj dos de 1,60 a $1,76 \mathrm{~kg}$. Obtiverarn pequenas diferenças entre pesos médios nas diferentes densidades de plantas, mas a pro duçấo foi maior nos pilantios mais densos. Recomendaram o plantio de filas duplas espasadas de $1,00 \mathrm{~m}$ entre canteiro, 
0,30 a $0,35 \mathrm{~m}$ entre ifileiras e $0,60 \mathrm{~m}$ entre plantas na file ra, o que corresponde a 35714 - 41660 plantas por hectare, aproxinadamente.

Segundo PY e PISSEAU (1965), em idênticas condições, além de certo limite, no que se refere à densidade de plantio, o peso médio do fruto é, evidentemente, tanto menor quanto maiss elevada é a densidade, enquanto a tonelagem por hectare aunenta até atingir un máximo, o que está de acordo com resultados experimentia is de MTTCHEII e NICHOLSON (1965), na A.ustrália, de BARBIER, na líartinica, de PENHOCK, em Porto Rico, e de PY e BARBISR, na Rlartinica; citados por PY e . TII STEAU (1965).

Para o cultivar 'Smooth Cayenne', Æeralmente, as linhas duplas são distanciadas de $90 \mathrm{~cm}$, a largura entre essas Ijnhas duplas varia de 30 a $4.5 \mathrm{~cm}$ e a distância entre as plantas de uma mesma linha é $x \in 30 \mathrm{~cm}$, ou seja, $90 \times 45 \times 30$ cm a $90 \times \because 0 \times 30 \mathrm{~cm}$, dando ui!a densidade de 494$) 0$ a 55000 plantas por hectare, de acordo com PY e IISSEAU (1965)。 COLTJTIS (1968), PY (1957) e CARDTHAIT. (1966a)dis correram sobre o efejto de diferentes espaçamentos, usados ein diversas partes do mundo: sobre o número e o peso dos frutos na colheita, como também sobre suas finalidades: consumo ao natural e industrjalizado. Os espaçamentos variaram de 0,50 a 1,50 m entre filciras duplas, de 0,30 a 0,66 m de largura entre as duas filejras e de 0,24 a 0,60 m entre plantas den tro das fileiras. Os majs usados e recomendados foram os se 
gujntes: $1,30 \times 0,20 \times 0,40 \mathrm{~m} ; 1,0 \times 0,30 \times 0,40 \mathrm{~m} ; 1,0 \times 0,60$ $\times 0,30 \mathrm{~m} ; 1,20 \times 0,40 \times 0,30 \mathrm{~m} ; 1,20 \times 0,30 \times 0,40 \mathrm{~m} ; 1,10 \times$ $0,50 \times 0,50 \mathrm{~m} \mathrm{e} 1,20 \times 0,60 \times 0,30$; o número de plantas por hectare variou de 15000 a 47000 , segundo as maiores autor dades em abacaxizeiros no mundo: GIACONELII e NONTEMERO, no Brasji; PY e PHIILIIPPE, na Guiné Francesa; WANG, CHAIIG, SU e YOSHIHARA, em Taiwan; COLIIIS, no Havaí, e AIIEIV, na lalásia, citados por CARIIHAII. (1966)。

CARDIIIAII: (1966) comparou, em diversas regiões produtoras mundiais, o efeito de diferentes espaçamentos, de 1,0 a $1,30 \mathrm{~m}$ entre fileiras duplas, de 0,20 a $0,60 \mathrm{~m}$ de larku ra entre as filejras e de $0,25^{\circ}$ a $0,40 \mathrm{~m}$ dedistância entre plan tas dentro das fileiras. A densidade de plantio variou de 25000 a $4 I 600$ plantas por hectare. Esse autor chegou às se guintes conclusões:

a) a djferença no número de plantas por unidade de área nâs foi suficiente pera que se pudesse determinar o inícic da competição;

b) dentro dos limites de 25000 a 41600 plantas por hectare, qualquer densidade poảe ser adotada sem prejuízo para o peso dos frutos:

c) os pesos médios dos frutos variaram de 0,945 a I,050 kg nas diferentes densidades de plantio.

Segundo JAIICK (1966), o aumento da população de plantas numa mesma área influi no desenvolvimento dos indivئ duos depoiss de atineido determinado ponto, em que cala planta 
passa a competir por fatores de crescimento, como luz, ácha e nutrientes. Esse ponto é chamado de ponto de competição. Iniciada a competição entre as plantas, o rendimento por ind víduo diminui. Porém, se a população aumenta o suficiente pe ra superar o decréscimo da produção por planta, o uso de ma or densidade aumentará a produção.

Estudos feitos por CAMTON (1957 e 1960) e FAIG e CHAITG (I958 e 1959), citados por CARDIIJAII: (I969), mostraram que a produscão cresce com o adensamento das plantas. Hesses estudos, as distâncias entre canteiros e entre plantas varia ram de 0,50 a $1,32 \mathrm{~m}$ e de 0,23 a $0,50 \mathrm{~m}$, respectivamente, pro porcionando populações de 25000 até 44893 pl.antas por hecta re.

WAIJG e CHAIIG (1959) estuảaram, em dois anos de produção, o efeito de densiade de plantás, com espaço de $0,50 \mathrm{r}$ entre fileiras e entse plantas nos canteiros e de 0,50 a $1,1.0 \mathrm{~m}$ entre canteiros. Tc primeiro ano, observaram um zü mento de produção de $48 \%$ para a população de 40 mil plentas, em relação à de 25 mil plantas, e una djminuição no tamanho e no peso médio das plaṇtas nas populações maiores.

SU (1957), em trabalho experimental conduzido na Estação Experimental de ToumLiu, China, verificou a importân cia de diferentes espaçarnentos e aảubaçóes, que infiuem no rendimento total e o peso médio dos frutos do cultivar'smooth Cayenne'. Utilizou os seguintes espaçamentos: $120-60-36$ cm (29 340 plantas por hectare); $90-60-36 \mathrm{~cm}$ (35 400 plan 
tas por hectare) e $90 \approx 60-30 \mathrm{~cm}$ (42 250 plantas por hecta re), chegando às seguintes conclusões:

a) o tamanho do fruto decresceu com o aumento da densidade de plantio por causa do decréscimo da quantidade de fertilizantes disponíveis para cada planta;

b) no espaçamento de $90-60-30 \mathrm{~cm}$, (teoricamen te) 42250 plantas por hectare foi a melhor densidade de plan tio, do ponto de vista do rendimento e peso dos frutos e tom bamento. Comportamento semelhante pode ser obtido con o uso de 36000 a 38000 plantas por bectare, desde que os nutrien tes (N, $\mathrm{I}_{2} \mathrm{O}_{5}, \mathrm{~K}_{2} \mathrm{O}$ ) disponíveis para a planta sejam suricien tes, podiendo aumentar o rendimento e o peso dos frutos.

Sobre espaçantos usados no Brasil, segundo CAR DINAII: e SIIVA (1964), há a penas recomendações práticas, va riaudo a população de 16000 a 33000 plantas por hectare. Im Iines Gerais, as populações observadas variaram de 15000 ? 33 300 plantas por hecta.'e, com yredominância de popruaçôes de 20000 plantas. Os plantios eram feitos em filas duplas e os espaçamentos entre canteiros variavam de 1,20 a $2,00 \mathrm{~m}$; en tre fileiras no canteiro, de $0,20 \mathrm{~m}$ a $0,30 \mathrm{~m}$, e, dentro das fi leiras, de 0,40 a $0,60 \mathrm{~m}$. Ainda, CARDINAIII. (1966) conclui.u, de resultados experimentais, que, dentro dos limites de 25000 a 41600 plantas por hectare, qualquer número de plantas pode ser adotado sem prejuízo para o jeso dos frutos. Was (1969) estudou, em Pekran Nenas, Johore, lialásia, o efeito de duas densidades de plantio, II 000 a 4.3000 
plantas por acre $\left(4046,84 \mathrm{~m}^{2}\right)$, com a variedade 'Singapore Spanish', utilizando mudas-filnotes de tamanho uniforme. Obte ve os seguintes resultados:

a) nas densidades de $12446,18668,23760$

29 040, 34 848, 43560 plantas por acre obteve os seguintes pesos nédios de frutos: $0,890,0,870,0,785,0,844,0,763$ e $0,695 \mathrm{~kg}$, respectivamente.

b) houve um pequeno decréscimo do peso médio dos frutos com o aumento da densidade, sendo aconselhável, para as condições do trabalho, uma população de 29040 plantas por acre.

0 autor citou, como vantagern de maior densidade, rendimentos mais altos, baixa infestação de ervas daninhas e menor custo de produção.

Utilizando densidaçes de $15000,20000,33000$ e 41 600 plantas por hectare, WHEl.O et alij (1974) obtireram: , com a rariedade espanhola 'Reä Spanish', em Cuba, os seguin tes peisos médios de frutos, com coroa: $0,912 \mathrm{~kg}$, na densidade de 15000 plantas por hectare; 0,908 kg, com 33300 plantas. por hectare; $0,996 \mathrm{~kg}$, com 20000 plantas por hectare; 1,020 kg, com 15.600 plantas por hectare. Não houve diferen ça significativa, para o peso médio dos frutos, entre as dife rentes densidades de plantio, mas o rendinento por hectare foi altanente significativo.

CARDINALI (1969) vitilizous em trabalho experimen tal, em Vespasiano, Minas Gerai.s, a variedade 'Iaßoa Santa' - 
Massa fmare la: Os espaços entre os canteiros verieram de 1,25 e 1,50 $\mathrm{m}$; entre as fileiras no canteiro, de 0,75 e $0,50 \mathrm{~m}$. A variação da distância entre as plantas dentro da fileira foi de $1,00-0,66-0,50-0,40$ e $0,33 \mathrm{~m}$, proporcionando den sidades de 10 a $30 \mathrm{mil}$ plantas por hectare, com intervalos de aunento de $5 \mathrm{mil}$ plantas por tratamento. Dos resultados che gou as seguintes conclusões:

a) o núrnero total de frutos aumentou proporcional mente ao aumento da pópulação de plantas;

b) o peso médio dos frutos não foi influenciado sisnificativamente pela densidade, apesar de se ter observado un lirgeiro decréscimo en seu valor. Toram obtidos frrutos com pesos médios de 0,900 a $1,025 \mathrm{~kg}$ :

c) o esquena de plantio com maior distância entre fileiras e menor distância entre canteiros apresentou resulta dcs estatisticanente sj.onificantes em relação ao número de fratos prociuzidos, não mostrando, poróm, resultados estitisti camente diferentes para os pesos médios dos frutos e para a produção total.

Com a variedade de abacaxi 'Red Spanish', em Cuba, comparando diferentes densidades de plantios, 15000,20000 , 33000 e 41600 plantas por hectare, GCNZAIES e GOIEZ (1974) concluírarn que o rendimento aurnentou àe maneira altamente significativa, enquanto os pesos médios dos frutos, com a co roa, não ajpresentararn diferenças sjenificativas entre si, va riando ae 1,16 a $1,25 \mathrm{~kg}$.

GIACOMtLII (1972) estudou o efeito de diferentes 
espaçamentos, utilizando o cultivar "Smooth Cayenne', no dis trito de Taquaral, município de Pitangueiras, são Paulo. Os espacamentos estudados foram os seguintes: $0,90 \times 0,30 \times 0,30$ $\mathrm{m} ; 0,90 \times 0,45 \times 0,30 \mathrm{~m} ; 0,90 \times 0,45 \times 0,45 \mathrm{~m} ; 1,35 \times 0,30$ $\times 0,30 \mathrm{~m} ; 1,35 \times 0,45 \times 0,30 \mathrm{~m}$ e $1,35 \times 0,45 \times 0,45 \mathrm{~m}$. Fsise autor chegou às seguintes conclusões:

a) o peso médio dos frutos, sem a coroa, variou de 1,57 a $1,91 \mathrm{kE}$, nos diferentes espaçamentos;

b) não houve aiferença significativa entre os tra tamentos quanto às percentagens de frutos de 1,50 a $2,00 \mathrm{~kg}$;

c) todos os espaçanentos proporcionaram frutos de peso que pode ser considerado satisfatório para os mercados internos.

IUCHI (1978) utilizou para o cultivar. 'Smooth Cay. enne', em Visconde do Rio Bánco, Minas Gerais, o esfaçamento de 1,2$) \mathrm{m}$ entre fileiras duplas, 0,40 netros entre as linkas consituintes das duas fileiras e $0,30 \mathrm{~m}$ entre plantas nas Ii nhas, permitindo 41000 plantas por hectare, obtendo, cos plan tios convenientemente adubados, frutos com peso nédio de 1,55 a $1,89 \mathrm{~kg}$.

Segundo GIACOLIIII (1972), na literatura brasile ra nada consta a respeito de trabalhos experimentais sobre es paçamento de plantio para o cultivar 'Śmooth Cayenne', tendo sido o seu primeiro trabalho. 


\subsection{Efeito dos diferentes pesos de mudas sobre o peso mé dio dos frutos}

PY et alii (1957), num ensaio de verão, com a va riedade 'Baronne de Rothschild', utilizando mudasmilhotes de tamanho médio, 300 a 400 g com 35 a $40 \mathrm{~cm}$ de comprinento, che garam aos seguintes resultados:

a) mudas tratadas com acetileno 13 meses depois do plantio (agosto de 1953), produziram frutos com peso méoio de $1 ., 158 \mathrm{~kg} ;$

b) mudas tratadas com acetileno 15 - 16 meses depo is do plantio (outubro-novembro de 1953) deram frutos com pe so médio de I, $164 \mathrm{~kg}$;

c) mudas com o mesmo peso, plantadas na mesma épo. ca, apresentaram 80\% de flocoscimento natural em 24/2/54.

Ainda PY et alii (1957), noutro estudo, classif cou mudas da variedade 'Smooth Cayeme', tipo filhotes, por peso e tamanho. Ii udas pequenas, 200 a $300 \mathrm{~g}$ ou 30 a $35 \mathrm{~cm}$; mudas médias, 300 a 400 g ou 35 a $40 \mathrm{~cm}$; e mudas grandes, 400 a 500 g ov 40 a $50 \mathrm{~cm}$. O florescimento das mudas-filhotes foi de 80\%, no mesmo período de indução natural de inflorescêncikl. Afirmam que, se plantas pequenas e pouco desenvol vidas forem induzidas a florescer, produzirão frutos pequenos: as crandes produzirão frutos majores. 0 tamanho e o peso fi nal do fruto tendem a ser determinados, em parte, pela área foliar capaz de suprir o fruto de alimentos or ênicos. 
0 plantio de mudas mais pesadas tern como resuitua do maiores plantas para a aplicação de ANA (ácido naftaleno a cético), dando, em conseqlência, frutos maiores, segundo IIT CHEII (1962)。

WANG e KroNG (1966) estudaram, en condições expe rimentais, em Taitung, o comportamento de diferentes pesos de mudas de abacaxizeiro, separandomas, para plantio, em 5 clas ses: $450-490$ g, 330 - 380 gs 250 - 300 g, 210 - 230 \& e 140 - $180 \mathrm{\xi}$. Chegaram às seguintes conclusões:

a) as mudas mais pesadas proporcionam naior desen volvinento e peso das plantas;

b) a diferença na percentagern de irutificação das plantas, em função dos diferentues pesos de mudas estudados, foi muito pequena ( 140 a 490 g), em plantio de outono;

c) o tamanho e a peso médio dos frutos aumentaram em consequência dos aumentos crescentes dos pesos das rnucias usadas no plantio;

d) mudasmilihotes com peso médio de 330 a 380 g são melhores para o plantio de outono.

PY e TISSEAU (1965), em trabaltho de classificação dos diversos tipos de mudas de abacaxi, por peso, de acorde com suas reservas ami.láceas, concluíram que o peso da muda, no plantio, influencia grandemente a taxa de crescinento da plan ta. O ideal. é que o florescimento se verifique em jlantas sㅡㅡ ficientemente desenvolvidas, porém não em plantas muito peque nas nem excessjvamente desenvolvidas. 
Para exportação ao natucals é desejável a obten ção do maior número possível de frutos con 1,30 1,50 kg. Os abacaxis mais saborosos são aqueles que têm de 1,30 a $1,30 \mathrm{ksg}$ segundo PY E TISSEAU (1965) e HAITIDIER e PY (1971).

PY (1964) conduziu trabalino experinental en Basse Pointe, ilartinica, empregando diferentes tipos de mudas de aba caxi da variedade 'Snooth Cayenne', com pesos diferentes no plantio, e deixou que as plantas florescecem naturalmente, ob tendo os seguintes resultados:

a) mudas de $150 \pm 50 \mathrm{~g}$ deram, na colheita, frutos com peso médio de $1,240 \mathrm{~kg}$, sem a coroa;

b) mudas de 500 t $100 \mathrm{~g}$ deram, na coIheita,frutos com peso médio de $1,547 \mathrm{~kg}$, sem a coroa.

Para a Ilartinica, aconselha o plantio de mudas de coroa e Ijilhotes, selecionalas por tipo e peso. 0 peso de ca da tiju de muda deve ser obstrrvado em relação a cada átía de plantio, para evitar a formação de frutos prematuros, :sem va lor comercial.

REYNHARDT (1968), que utilizou diferentes tipos, tamanhos e pesos de mudas do cultivar 'Smooth Cayenne', na. África, concluiu que o melnor tipo de muda para plantio é c filhote da base do fruto, com tamanho médio de $32 \mathrm{~cm}$ e $300 \mathrm{cos}$ - qual produz frutos de tamanizo comercial acina de $1,40 \mathrm{~kg}$. PY et alii (1963) conduziram experimentos em Glua dalupe, con a variedade 'Smooth Caycnne', utilizando filhotes e rebentos com $300 \pm 100 \mathrm{Eg}, 500 \pm 3.00 \mathrm{~g}$ e $700 \pm 100 \mathrm{E}$. $\mathbb{R}_{0}$ 
ram feitos plantios em 4 épocas diferentes: outubro de 1962 , janeiro de 1963, abril de 1963 e julho de 1963. Os autores chegaram aos seruintes resultados:

a) as mudas plantadas em outubro de 1962, com pe sos de $300 \pm 100 \mathrm{~g}$, produziram frutos com peso médio de 1,986 $\mathrm{kg} ;$ as de $550 \pm 100 \mathrm{~g}$, frutos de $2,060 \mathrm{~kg}$; e as de $700 \pm$ $100 \mathrm{~g}$ s frutos de $2,008 \mathrm{~kg}$;

b) as mudas plantadas em janeiro de 1963, com pe sos diferentes, produziram frutos com pesos médios de 1,952lrs, I,982 $\mathrm{kg}$ e I,982 kg;

c) as mudas plantadas em abril de 1963, com pesos diferentes, produziram frutos com pesos médios de $1,724 \mathrm{~kg}$, $1,664 \mathrm{~kg}$ e $1,632 \mathrm{~kg}$;

d) as mudas plantadas em julho de 1963, com pesos di:erentes, produziram frutos com resos médios de $1,73 \% \mathrm{kr}$, $1,6 C 3 \mathrm{~kg}$ e $1,460 \mathrm{~kg}$;

e) é muito inporta:ıte conhecer as condiçñes cliná tica de una região, para que su possa escolker os melłores ti pos, pesos de mudas e épocas de plantio, o que permite a obtenção de plantas suficientemente desenvolvidas, antes̃ de um período de dias curtos, para evitar formaço de infilorescềi cia prematuras, que darão orịem a frutos pequenos, sem valor comercial.

Os resultados desse trabalho foram confirmados jor GrILIARD (1969), que estudou, en Cameron, a influêncja da deta de plantio e de diferentos pesos de mudas sobre o conporta 
mento do abacaxizejro. Utilizou, no plantio, mudas com peso de $200 \mathrm{~g} \pm 10 \%, 350 \mathrm{~g} \pm 10 \%$ e $500 \mathrm{~g} \pm 10 \%$. As datas de plan tio foram, respectivamente: 15/02/66; 15/05/66 e 15/10/66 e 15/11/66, Obteve, na colheita, para as diferentes condições de insolação e precipitação durante as épocas de plantio, pe ríodo de desenvolvimento e colheita dos frutos, os seguintes resultados:

a) frutos de mudas plantadas em 15/02/66, com pe sos de $\pm 200 \mathrm{~g} \pm 10 \%$, 350\% $\pm 10 \%$ e $500 \mathrm{~g} \pm 10 \%$, deram, na co Jheita, pesos médios de 1,03 kg, 1,24 kg e 1,36 l.rg:

b) frutos de mudas plantadas em 15/05/66, com pe. sos diferentes, deram. na colheita, pesos médjos de $1,01 \mathrm{~kg}$, $1,14 \mathrm{~kg}$ e $1,18 \mathrm{~kg} ;$

c) frutos de nudas plantadas em 15/10/66, com pe sos rj.ferentes deram, na colheita, pesos médios de $1,26 \mathrm{~kg}$. $1,49 \mathrm{~kg}$ e $1,55 \mathrm{~kg}:$

d) frutos de mudas plantadas em 15/11/66, com pe, sos diferentes, deram, na coltheita, pesos médios de $1,25 \mathrm{~kg}$, $1,52 \mathrm{~kg}$ e $1,69 \mathrm{~kg} ;$

e) notou-se, claramente, o aumento signifjcativo dos pesos nédios dos frutos de acordo com as épocas de plan tio e à medida que se aumentou o peso das mudas até 500 \& $10 \%$

Estudando as melhores datas de plantio de abacaxi na Viartinica, PY (1.970) utilizou diferentes tipos e pesos de radas da variedade 'smooth Cayenne', rilhotes, rebentos poque 
nos (200 a 300 g), rebentos médios (400 a 500 g) e rebentos grandes $(600$ a $800 \mathrm{~g})$, que foram plantados em diferentes épo cas do ano: Concluiu que os fatores que influenciam o maior ou menor desenvolvimento das plantas, as épocas de florescimento e o peso dos frutos colhidos são os seguintes:

a) fatores climáticos da ręião: o comprimento do dia é o fator que mais influi na indução naturaj da inflores cência, vindo em seşuida a ternperatura, consicerando as épo cas de plantio, os timos, tamanhos e pesos de muảas;

b) sendo planta de dia curto, a maior indução na tural de florescimento no abacaxizeiro se verifíca quando os dias são menores e as temperaturas mais baixas;

c) em regiões altas, deve-se tomar cuidado com lun segundo período natural de indução de inflorescência, que se veririca no verão, com o aparecimento de dias nubladus, chuvo sos e com redução de temperat rra, que deve produzir o mesmo efeitc dos dias curtos da estação fria. Isso influirá no pe so médio dos frutos na colneita, se plantas pouco desenvolvidas forem induzidas ao florescimento.

TAY e VIEE (1976) estudaram o efeito comparativo do plantio de diferentes tipos e tanánhos de muảas sobre o rena mento e a qualidade dos frutos do abacaxizeiro. Utilizaram mu àa-fjuhotes, rebentos e coroas com 24 e $40 \mathrm{~cm}$ de comprimento. obtiveram os seøuintes pesos médios dos frutos, na coljhejta:

a) mudas de coroa com 24 cn produziram frutos de I,I4 $\mathrm{kE} ;$ as de $40 \mathrm{~cm}$, frutos de $1,25 \mathrm{~kg} ;$ 
b) as de filhotes com $24 \mathrm{~cm}$ broduziram frutos de $1,07 \mathrm{~kg} ;$ as de $40 \mathrm{~cm}$, frutos $1,09 \mathrm{~kg} ;$

c) as de rebentos con $24 \mathrm{~cm}$ deram Irutos de 0,85 $\mathrm{kg}$; as de $40 \mathrm{~cm}$, frutos de 0,95.

Im Iinas Gerais, Viçosa, FORrTs e ANDirRSEN (197J.) utilizaram mudas-filhotes com $20 ; 25,30,35,40$ e $45 \mathrm{~cm}$, da variedade 'Pernambuco Massa Amarela' (Iagoa Santa), e chege ram às seguintes conclusões:

a) o tamanho das mudas no plantio influenciou sig nificativemente o número a o peso médio dos frutos produzidos 19 meses depois;

b) as mudas de $20 \mathrm{~cm}$ produziram, na colneita, frü tos com peso médio de $0,572 \mathrm{~kg}$; as de $25 \mathrm{~cm}$, frutos de $0.538 \mathrm{~kg}$; as de $30 \mathrm{~cm}$, frutos de $0,777 \mathrm{~kg}$; as de $35 \mathrm{~cm}$, frutos de 0,960 $\mathrm{kg}$; as de $40 \mathrm{~cm}$, frutos de I, I35 kg; e as de $45 \mathrm{~cm}$, frúcis de $1, ? 18 \mathrm{igg}$.

GIACONEIII (1972) es iudou o efeito de diferentes espaçanentos sobre a qualidade do fruto do cultivar 'Smooth Cajenne'. Utilizou mudas-rebentos de 500 a 600 gramas, obten do, na colheita, frutos de pesos médios, sem a coroa, de 1,57 a 1,9! kg. Não houve diferença sienificativa entre os dife rentes espaçamentos quanto às percentagens de frutos de 1,5 a $2,0 \mathrm{~kg}$. Houtro trabalno, utiljzou diferentes épocas de plantio, de mesma variedade, com mudasomebentos de 300 a 400 gramas, obtendo, na colheita, frutos con peso mécía, sem a coroa, de 1,43 a $1,33 \mathrm{~kg}$, nas diferentes épocas de plantio e 
de estímulo para o florescinento natural das plantas, quando elas apresentavar desenvolvjmento vegetativo (massa foliar teórica) diferente. Consęuiu produção de frutos com 1,83 kg de peso médio, sem a coroa, em plena época de entressa fra, para as condições do planalto paulista.

Em Minas Gerais, Visconde do Rio Branco, IUCEI (1978), utilizando mudas da variedade 'Smooth Cayenne', com 35 a $40 \mathrm{~cm}$, obteve, na colheita, em plantio convenientemente aduibado, frutos com peso médio de 1,73 a $1,88 \mathrm{~kg}$.

3.5. Efeito dos teores de nutrientes da folha "D" sobre o peso médio dos frutos

SAITUEIS et aIii (I955) estudaram o efeito de di ferentes níveis de $\mathbb{N}, P$ e $K$ sobre a produção da varieciade de abac xi 'Red Spanish', elı Porto Eico. Analisou a folhei "D" 8 meses depois do plantio e chegou às seguintes conslusiões:

a) valores de $N$ abairo de $1,66 \%$, na folha "D", indicam resposta positiva, com aumento de produçãos quando se aplica nitrogênio:

b) valores de $\mathrm{P}$ de $0,17 \%$ ind icam que não ocorre a umento significativo na produção quando se aplicam fertili zantes fosfatados;

c) valores de $\mathbb{K}$ acjma de $4,25 \%$ indicam que não há a unento significativo na produção quando são aplicados fer tilizantes potássicos. 
Os níveis de nutrientes definidos como ideais, na folha "D", para obtenção de bons rendimentos nas varieda des de abacaxizejro 'Red Spanish' e 'Smooth Cayenne', segun do SAMUEISS e DTAZ (1960), citados por SARUEIS et alii (1955), são os seguintes:

$\begin{array}{lll} & \text { 'Red Spanish' } & \text { 'Smooth Cayenne' } \\ \text { IN } & 1,7-2,2 \% & 1,6-1,9 \% \\ \text { P } & 0,20-0,25 \% & 0,16-0,20 \% \\ \text { K } & 3,5-4,0 \% & .1,8-2,5 \%\end{array}$

SU (1956), em trabalho realizado ern Taiwan, Chi na, estudando a influência da fertilidade do solo e da nutrị cão da planta sobre o rendinento e as proprieảades dos fru. tos do abacaxizeiro, obteve os seguintes resultados, analisan do os teores de iN, $P$ e $K$ nas folhas "J" das plantas:

a) Irutos com pesi médjo de $1,180 \mathrm{~kg}$ apresenta ram cis seguintes teores, em ppm: 1.197 de $\mathbb{N O}_{3}-\mathbb{N}, 255$ de $P$ e $10 \approx 80$ de $\mathrm{K} ;$

b) frutos com peso rnédio de 1,2601rigapresentaram. 954 de $\mathrm{NO}_{3}-\mathrm{Ng}, 285^{\circ}$ de $\mathrm{P}$ e 1.370 de $\mathrm{K}_{9}$ ern ppm;

c) fruto: com peso médio de $1,250 \mathrm{~kg}$ apresenta ram 1.188 de $\mathrm{IO}_{3}-\mathrm{I}$, 170 de $\mathrm{P}$ e 2.260 de $\mathrm{K}$, em jopm;

d) frutos com peso médio de $1.390 \mathrm{~kg}$ apresenta ram 990 de $\mathrm{NO}_{3}-\mathrm{N}, 220$ de $\mathrm{P}$ e 3.250 de $\mathrm{K}$, ern plpm;

e) Irutos com peso módio de $1,4.00 \mathrm{hrg}$ apresentaram 1.215 de $\mathrm{NO}_{3}-\mathrm{N}, 180$ de $\mathrm{P}$ e 2.750 de $\mathrm{K}$, em prm;

f) frutos com peso mécio de $I, 490 \mathrm{~kg}$ apresentaram 
1.215 de $\mathrm{IN}_{3}-\mathrm{H}, 200$ de $\mathrm{P}$ e 3.250 de $\mathrm{K}_{9}$ en pom。

De acordo com as análises foliares, as plantas de abacaxizeiro bern nutridas apresentaran os seguintes teores de nutrientes nas folhas: 1,5 a $2,0 \%$ de $\mathrm{I}_{9} 0,7$ a $0,3 \%$ de $P$ e 3,5 a 4,0\% de $K$, segundo trabalho de PAN (1957), em Taj wan, China.

KAIAPATHY (1958), na halásia, por meio de análi se foliar da variedade' 'Singapore Spanish', recomendou, pre liminarmente, que, para obter o máximo de rendimento e quali dade dos frutos, a Iolha "D", depois de analisada, deverá ter, aproxinadamente, as seguintes percentagens de nutrien tes: $1,2 \pm 0,2 \%$ de $\mathrm{H}, 2,2 \pm 0,3 \%$ de $\mathrm{P}$ e $32,0 \pm 4 \%$ de $K_{0}$ A relação $K / P$ deverá estar o rnais próximo possivel de 14. TAY et aliji (1.969), na lialásia, con a variedade de ahacaxizeiro 'Singapore 'spanish', procuracam estabelecer correlação entre os teores de $H_{y} P$ e K, na foltha "D", median te análise foliar, em relação ao renaimento e ao contı́́do de a çúcar e ácido dos frutos. Utilizaram follhas com 3, 4, 5, 6, 7 e 8 meses de idade para as análises, chegando às seguintes conclusões:

a) de modo geral, não houve correlação entre te or de if da folna e rendjmento, conteúdo de açúcar e ácido dos frutos:

b) para o teor de I na f lha, não foi observada correlação consisterite;

c) para o teor de Ir na folha, houve Erandie corre 
lação eñ quase todos os casos.

$$
\text { GODTREY - SAPI - AGGRPY (I970), em análises IOlia }
$$
res da Polisa "D", da variedace de abacaxi 'Sugarloaf', reali zadas em Ghana, visando a estabelecer un guia para a nutri ção de abacaxizeiros, concluiu que os níveis de nutrientes na seção basal da referida folha que corresponōem aos máxj. mos rendinentos, corn frutos de peso médio de $1,680 \mathrm{~kg}$ a 1,860

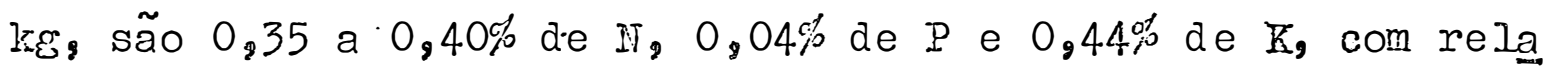
̧̧ão $K / P$ àe 11,2 a $11,5: 1$.

Teores de 0,88 a $1,03 \%$ de $i, 0,29$ a $0,39 \%$ de $P$, 2,65 a 3,05\% de $K, 0,12$ a $0,16 \%$ de $\mathrm{Ca}$ e 0,12 a $0,14 \%$ de $\mathrm{IIg}$ foram encontrados em análises foliares da foltha "Di", por IU-m CHI (1978), que utilizou, nas análises, a parte aclorofilada de: citada folha. O trabalho experinental foi conduzido em Vistonde do Rio Branco, Minas Gerais, com a variedade de aba ca. :i 'Smouth Cayenne'. Dentro desses linites dos teores de nutrientes de folha "D" foram obtidos frutos com pesc médio de 1,54 a $1,88 \mathrm{kr}$ 。 


\section{MATERTATS E MÉTODOS}

\subsection{Iocalização do experimento}

0 experimento foi instalado na Istação ixperjnẹ tal de Visconde do Rio Branco, Minas Gerais, em regiao de clima tipo Cwa, de acordo com a classificação de kßppen, a qual tem por coordenadas geográricas $21^{\circ} 07^{\prime}$ de latítude Sul, e $43^{\circ} 57^{\prime}$ de Jongitude Ceste a $4.00 \mathrm{~m}$ de altitude.

Na Tabela $I$ encor tram-se as médias n. znsais, de novembro de 1972 a janeiro de 1975, das características cIj máticas da referida ręião.

4.2. Haterial

4.2.1. Características do clina e do solo

Considerando dados de 29 anos, o local apresenta uma média de $79,5 \%$ de umidade relativa, 1272,6 min de precipitação anual média, $15 \mathrm{~mm}$ ocorrendo no mês mais seco, e ten peratura média de $21,7^{\circ} \mathrm{C}$, com mínima de $16,3^{\circ} \mathrm{C}$ e máxima de 


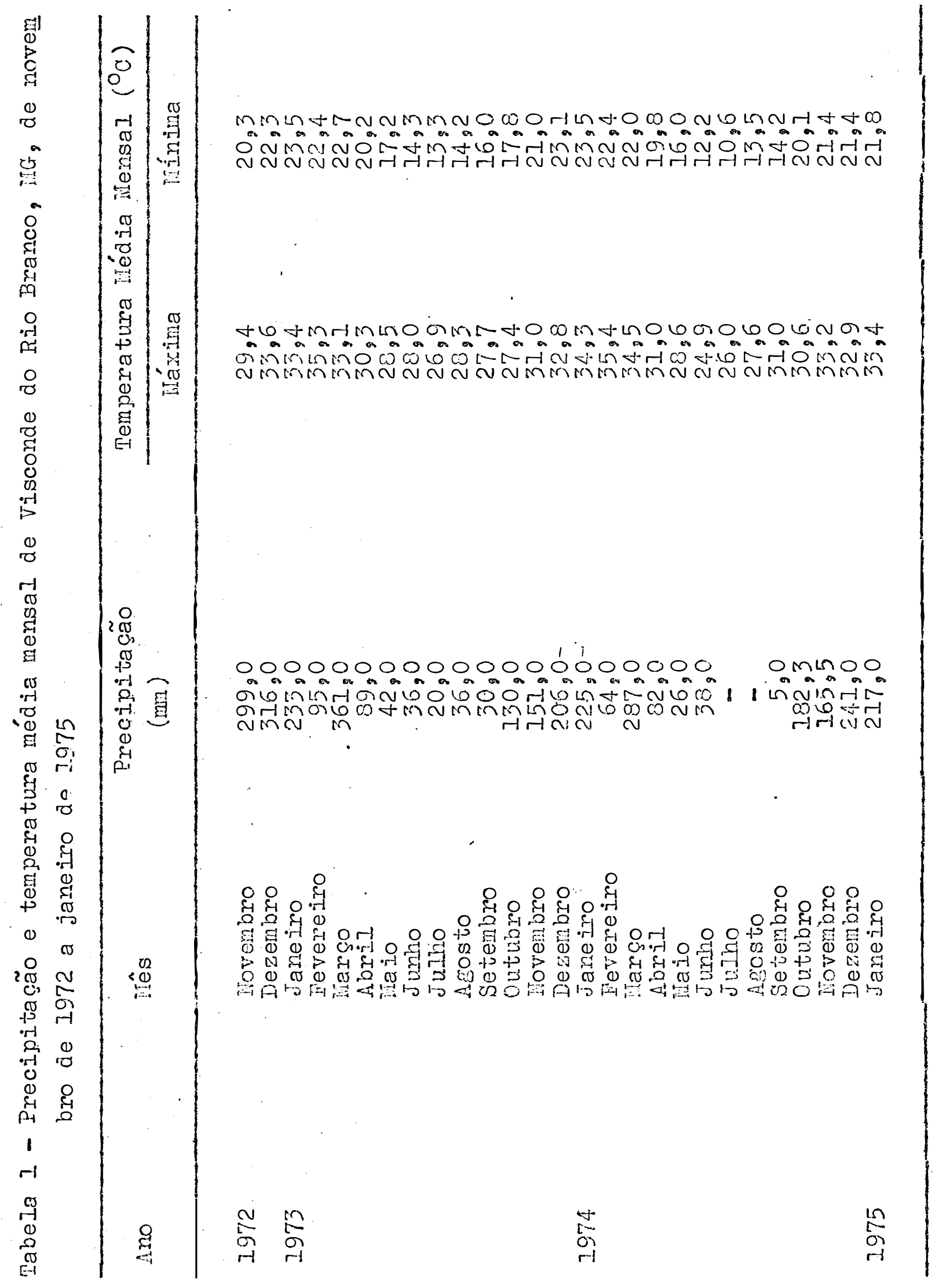


$29, I^{\circ}$ C. O solo da área experjuental foi classificado cono Iatossolo VermeJho-imarelo Distróicico. Suas características Lísicas e quj́micas estão relacionadas na Tabela 2. As análij. ses de solo foram feitas utilizandomse amostras retiradas de uma profunàidade de $0-20 \mathrm{~cm}$, onde se localizam usualmente as raízes do abacaxizeiro. A área experimental apresenta expo sição norte e declividade de $12 \%$ 。

\subsubsection{Planta}

Foi utilizada a de abacaxizejro 'Smooth Cayenne'. Utilizaram-se "mudas de cacho", filhotes da base do fruto e do pedúnculo, que foram retiradas do pedúnculo, na base do Iruto, e dejxadas paramuxcharà sombra ảurante 60 dias, para ficilitar seu mane.jo no plarıtio.

Foram selecionadas mulas com quatro pesc s dize rentes:

$$
\begin{array}{ll}
200 \text { a } 250 \mathrm{~g} & 400 \text { a } 450 \mathrm{~g} \\
300 \text { a } 350 \mathrm{~g} & 500 \text { a } 550 \mathrm{~g}
\end{array}
$$

Depois àa murchidão, as mudas foram seleciona das. A sezuirn, fez-se a remoção das follhas basais e a ine são em solução de funcicida mercurial neatina $(2,5 \%$ de mer cúrio) a cris, em mjstura com o inseticida Parathion (Foliuol is 60) a $0,7 \%$, aurante três minutos. 


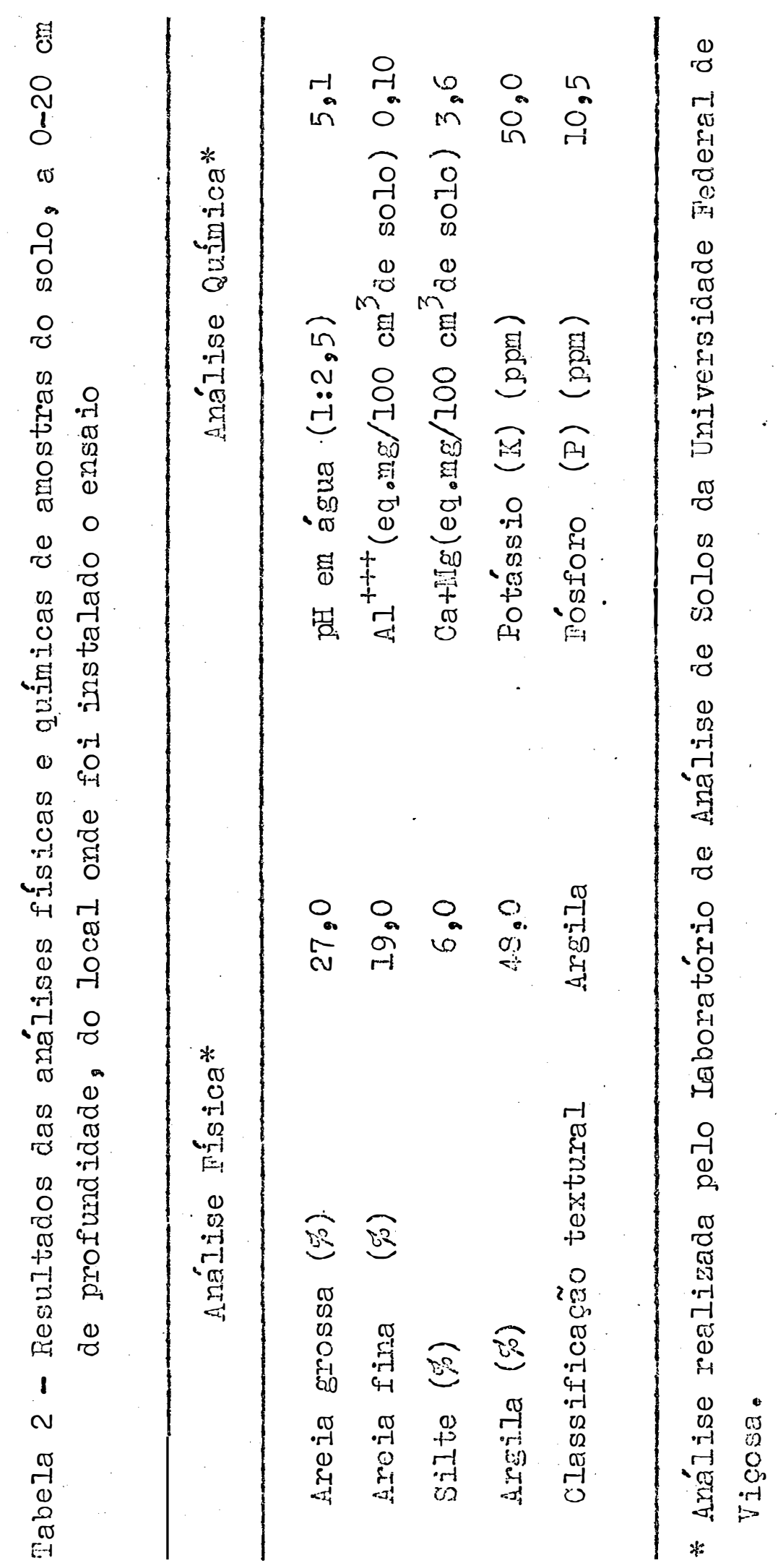


da em trabalhos anteriores, fejtoa por VASCOMCEINS (1952) , CARDTNAII (1969) e FORTSS (1971), utilizando 25.000 plantas por hectare foi a seguinte:

Sulfato de amônio $(20 \%$ de N) $=600 \mathrm{~kg} / \mathrm{ha}$

Superfosfato simples ( $16 \%$ de $\mathrm{P}_{2} \mathrm{O}_{5}$ ) $-300 \mathrm{~kg} / \mathrm{ha}$

cloreto de potássio $\left(60 \% \text { de } \mathrm{K}_{2} 0\right)^{5}-200 \mathrm{~kg} / \mathrm{ha}$.

4.3. Létodos

4.3.1. Delineamento experinental

Os tratamentos foram dispostos em parcelas sub divididas, no delineamento em blocos casulalizados, com 7 re petịcões e 12 plantas úteis por subparcela. As plantas IO ram dispostas em fileiras juplas, sendo os tratamentos cir cunciados por bordadura.

Nas parcelas fcram colocados os estaçanentos, em número de três:

$$
\begin{aligned}
& 120 \times 30 \times 40 \mathrm{crn}=33333 \mathrm{pl} / \mathrm{ha} \\
& 120 \times 40 \times 40 \mathrm{~cm}=31250 \mathrm{pl} / \mathrm{ha} \\
& 120 \times 50 \times 40 \mathrm{~cm}=2941 \mathrm{pl} / \mathrm{ha} \\
& \text { Tas subparcelas foram colocados os quatro dife } \\
& 200 \text { a } 250 \mathrm{~g} \quad 400 \text { a } 450 \mathrm{~g} \\
& 300 \text { a } 350 \text { \& } \quad 500 \text { a } 550 \text { ह }
\end{aligned}
$$
rentes pesos de mudas: 


\subsubsection{Instalação e condução do experimento}

Foram instalados dois experimentos, um em época chuvosa, 20 de novembro de 1972, e outro em época seca, 20 de abril de 1973. O terreno foi arado e gradeado, abrindose covas espaçadas de $120 \mathrm{~cm}$ entre fileiras duplas de plan tas de $30 \times 40,40 \times 40$ e $50 \times 40 \mathrm{~cm}$ entre plantas, dentro das fileiras.

A adubação foi feíta colocando-se, em cada cova de plantio, por planta, todo o superfosfato ( $12 \mathrm{~g})$, mistura do con $2,5 \mathrm{~g}$ de AJörim $5 \%$, visando a controlar o cupim。 0 sulfato de amônio $(24 \mathrm{~g})$ e o cloreto de potássio (24 g) fom ram misturados e aplicados em 3 partes: no plantio da época chuvosa, I/3 foi aplicado 30 dias depois do plantio (dezembrs de 1972), I/3 fol aplicazo no fim do período ckiluoso (ma:'̧o de 1973) e a última parte curante o período chivoso do mesmo ano (dezembro de 197:i); no plantio da época seca , $1 / 3$ foi aplicado no início dars chuvas (setembro), $1 / 3$ foi aplicado no fim do período chuvoso (março) e a última parte no infício das chuvas.

ilo plantio da época sech foram feitas 12 capinas manuais no da época chuvosa, 14.

Depois do aparecimento da inflorescência na roseta foliar, teve inficio um programa de controie da broca do fruto (Thecla basilides geyer), com pulverizações quinze nais de Parathion (Folidol $\mathrm{E}$ 60) a $0,2 \%$ e de espalhante Extravon - 200 a $0,01 \%$, até um mês depois do término da fase 
de florescimento。

$$
\text { 4.3.3. Ava.liações }
$$

Decorridos doze meses do plantio da época seca, fezmse a coleta das folhas "D" (localizada na 4 a camada de folha), nư total de 9 folhas por parcela, para análise de $\mathbb{I r}, \mathrm{P}, \mathrm{K}, \mathrm{Ca}, \mathrm{M}_{\mathfrak{F}}$ e $\mathrm{S}$, feita pelo Laboratório de Análise Quǵ mica do Solo da Universidade FederaI de Viçosa. Utilizou se somente a parte aclorofilada, que foi cortada em três parn tes iguais, no sentido horizontal, usando-se, na análise, apenas a parte mediana. A mineralização foi feita por via seca. O nitrogênio total ioi determinado pelo método de Kjeldahl, o Iósforo pelo método colorimétrico, o potássio pela fotometria de chama, o Ca e o ng por absorção atômica e o s por turbidimetria.

A colneita dos frutos do plantio da época chuvo sa foi seita de junho a agosto de 1974, quando foram colhi dos $64 \%$ dos frutos. O restante da colheita foi feito a par tir de dezembro do mesmo ano até fevereiro de 1975. A 2E collheita nẽo foi v.tilizada no presente trabalho.

A colheita dos frutos do plantio da época seca foi feita de dezembro de 1974 a fevereiro de 1975, época em que foram colnidios $85 \%$ dos frutos. O restante da colheita foi Leita de julho a arosto de 1975, nas também não foi usa da no presente trabalino. 
Os f'rutios das duas ajferentes épocas de pJantio foram colnidos quanỏo apresentavam coloração amarelomalaran jada, Ievando em conta que, na colheita em época rnais fria (plantio da época chuvosa), os frutos apresentavam colora ção mais intensa que na época nais quente (plantio da época seca).

Os parâmetros estudados foram: peso médio dos frutos, em função dos diferentes espaçamentos, peso das mudas nas duas épocas de plantio: no plantio da época seca, colheita Leita na época chuvosa, estudou-se também o efeito dos teores de nutrientes da folha "D", aos 12 meses depois do pjantio, sobre o peso médio dos frutos na colheita.

Para a pesagem dos frutos individualmente, dum rante os períoủos de colneita, foi utilizada uma balanca con precisão de 10 gramas.

Durante os mese 3 de colheita, dezembro, janeiro, fevereiro, junho, julho e agosto, foram determinados, também o brix, a acidez titulável e a relação brix/acides titu. lável dos frutos. 0 brix foi determinado por meio de um re. fratômetro de laboratório, enquanto a acidez foi determina da por titulação de $10 \mathrm{mI}$ de suço con $\mathrm{NaOH} \mathrm{O,IN,} \mathrm{fator.}$ 0,8665, utilizando-se fenolftaleína como inaicador。 


\subsubsection{Análises estatísticas}

Os efeitos de tratamentos qualitativos foram es tudados mediante análise de variância e teste de Tukey, ao nível de 5\% de probabilidade. As análises estatísticas dos resultados dos ensaios em que se estudavam tratamentos quan titativos foram efetuaỏas por meio da análise de recressão. A escolna do modelo îi baseada no coeficiente de determina ção corrigido ( $R^{\infty}$ ou $\bar{r}^{2}$ ), na significáncia da regressão, testada pelo teste Fo na significanncia dos coeficientes de regressão, testados pelo teste $t$, de "student", consiajerando un nível aceitável de até 10\% de probabilidade, segundo HICIS (1973), AIDISRSOIT e MCLEAT (1974), CHEV (1976) e PIVIEIS THI GOMES ( (1976)。

Para comparar oz efeitos das duas épocas

die plintios (seca e chuvos: $z$ ) subre o peso médio dos îrutos fi $i$ utilizada a variável "dummy", segundo BEIT-DATID e TOIIK (1975) e JOHnS'NOH (1963), em que se ajusta un único plano de regressão e ôele se extraem equações, pela substituição da variável qualitativa por variáveis codificadas quantitativamente. Esse método, além de permitir o uso da regres são, na presença de variáveis djocretas, é útil quando os graus de Iiberdade para estimativa do resíduo são poucos. Forar utilizados modelos que pernitiam variações simultâneas nas declividades e nos interceptos das curvas. 


\section{RESULTADOS}

5.1. Brix médio dos frutos:

Tabela 3 - Análise de variância dos dados relativivos ao efej to de épocas de collheita sobre o brix dos frutos

\begin{tabular}{|c|c|c|c|c|}
\hline $\begin{array}{l}\text { Fente de } \\
\text { Vertiação }\end{array}$ & G.I. & $\begin{array}{l}\text { Soma de } \\
\text { quadrados }\end{array}$ & $\begin{array}{l}\text { Quadrados } \\
\text { médios }\end{array}$ & $\mathrm{T}$ \\
\hline Repetição & 2 & 1,777780 & 0,888889 & \\
\hline ileses & 5 & $48,1] 100$ & 9,622220 & $11,94^{* * *}$ \\
\hline Erro & 10 & 8,055530 & 0,805553 & \\
\hline
\end{tabular}

*** Significativo, ao nível de loj de probabilidade.

De acordo com a análicise de varianncia dos dados relativos a brix dos frutos (Tabela 3), houve efeito signi- 
ficativo de épocas de colheita, ao nível de $1 \%$ de probabili dade.

Tabela 4 - Bfeito de épocas de coineita sobre o brix médio dos frutos

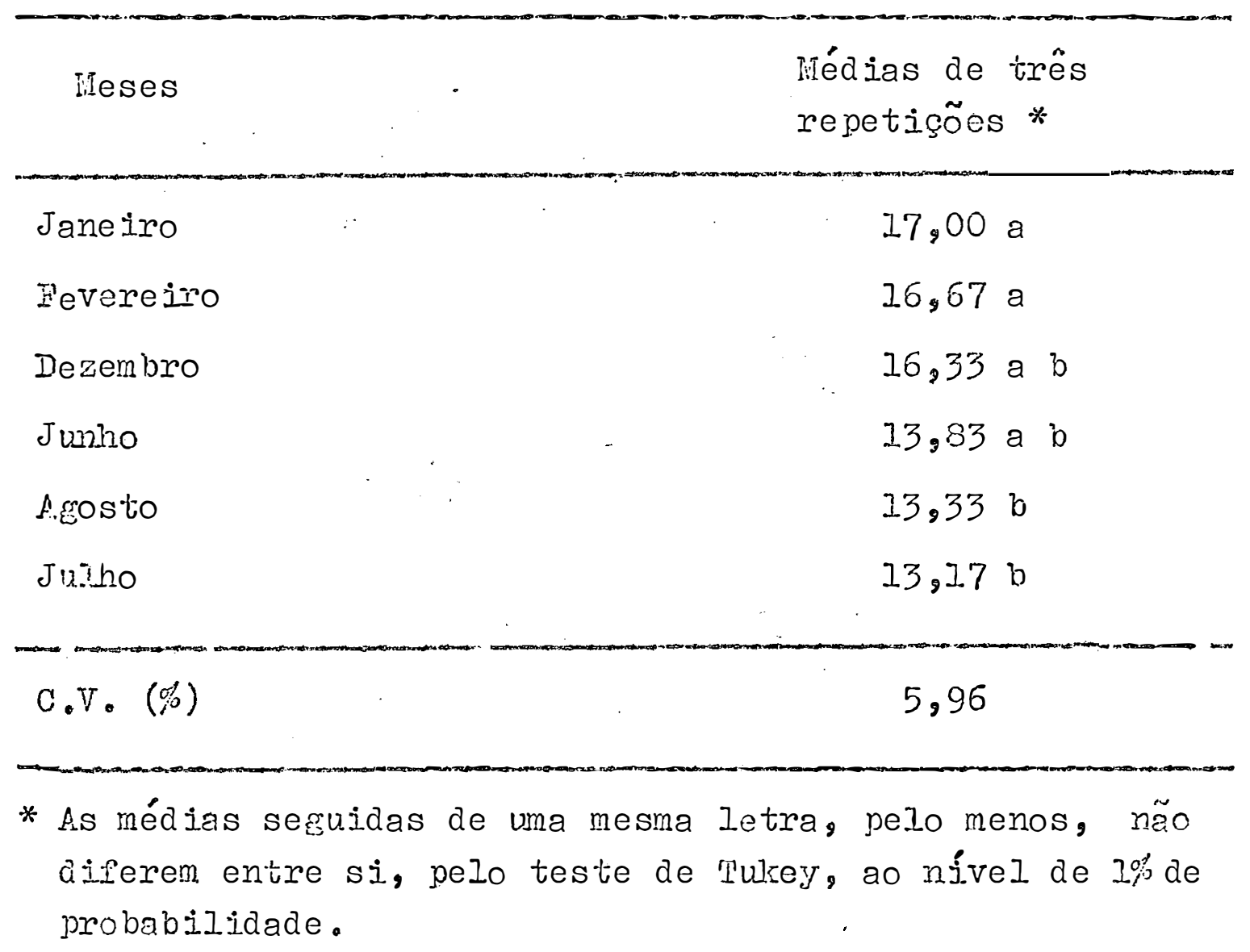


5.2. Acidez média tituláve1 dos frutos

Tabela 5 m Análise de variância dos dados relativos ao efe to de épocas de colheita sobre a acidez titulá vel dos frutos

\begin{tabular}{|c|c|c|c|c|}
\hline $\begin{array}{l}\text { Fonte de } \\
\text { Variação }\end{array}$ & $G_{0} I_{0}$ & $\begin{array}{l}\text { Soma de } \\
\text { quadrados }\end{array}$ & $\begin{array}{l}\text { quadrados } \\
\text { médios }\end{array}$ & T \\
\hline Repetịção & 2 & 4.001120 & 2,000560 & \\
\hline Ileses & 5 & $617: 210000$ & 123,442000 & $48,56 * * *$ \\
\hline Brro & 20 & 25,418500 & 2,541850 & \\
\hline$C . V .\left(c_{0}^{1}\right)$ & & & 13,26 & \\
\hline
\end{tabular}

*** Significativo, ao nível de 1 \% de probabilidade.

De acordo com a análise de variância dos dados relativos à acidez dos frutos (Tabela 5), houve efeito sjg nificativo de épocas de colheita, ao nível de l\% de probabi Iidade. 
Tabela 6 - Efeito de épocas de collueita sobre a acidez mé dia titulável dos frutos

\begin{tabular}{|c|c|}
\hline Meses & $\begin{array}{l}\text { Médias de três } \\
\text { repetições * }\end{array}$ \\
\hline Julho & 20,10 a \\
\hline Asosto & $17,20 \mathrm{a}$ \\
\hline Junho & $15,93 \mathrm{a}$ \\
\hline Fevereiro & $6,43 \mathrm{~b}$ \\
\hline Janeiro & $6,34 \mathrm{D}$ \\
\hline Dezembro & $6,00 \mathrm{~b}$ \\
\hline$C . V 。(\%)$ & 13,26 \\
\hline
\end{tabular}


Tabela 8 - Ifeito de épocas de coltheita sobre a relação brix/acidez dos frutos

\begin{tabular}{|c|c|}
\hline lieses & $\begin{array}{l}\text { 海édias de três } \\
\text { repetições * }\end{array}$ \\
\hline Dezembro & 2,96 a \\
\hline Janeiro & $2,67 a$ \\
\hline Ievereiro & $2,55 \mathrm{a}$ \\
\hline Junho & $0,93 \mathrm{~b}$ \\
\hline Agos to & $0,77 \mathrm{~b}$ \\
\hline JuIno & $0,67 \mathrm{~b}$ \\
\hline$C_{0} V \cdot(\%)$ & 22,50 \\
\hline
\end{tabular}

5.4. Efeito de espacamentos sobre o peso médio dos fru tos

Os espaçamentos estudados não influenciaram sig nificativam nnte, nos níveis preestabelecidos, o peso médio dos frutos. 


\subsection{Elejto de diferentes posos de mudas sobre o peso mé dio dos frutos}

\subsection{Plantio da época chuvosa}

Tabela 9 - Coeficientes de regressão estịnados $\left(\hat{b}_{j}\right)$, des vios-padrão desses coeficientes $\mathrm{s}\left(\hat{b}_{\dot{i}}\right)$, valores de $t$, de "Student", e coeficientes de determi nação $\left(r^{2}\right.$ e $\left.\bar{r}^{2}\right)$, para. pesos àe frutos de abaca xizeiro, em função de diferentes pesos de mu das, plantadas na época chuvosa

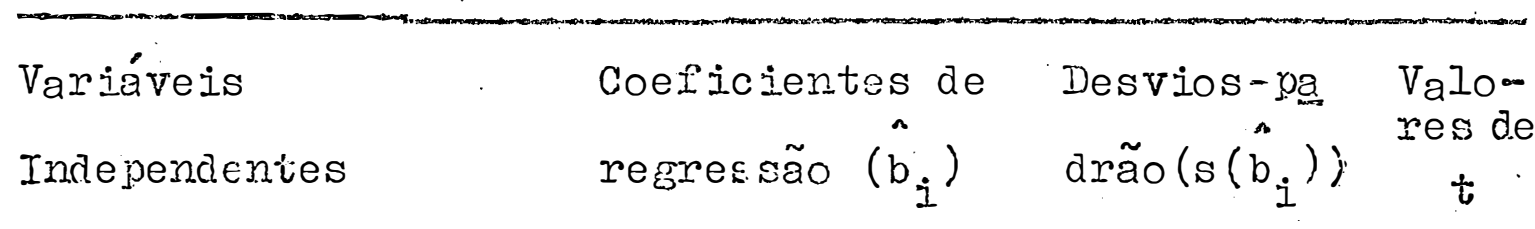

Yeso de muda $9, \therefore 6555$

$1,785 \div 9 \quad 5,1 \mathrm{C} * * *$

Peso de muda quadrático $-0,0103566$ $0,00236394,38 \% *$

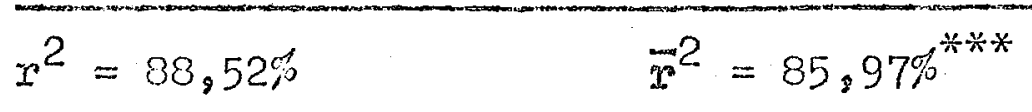

$* * *$

"Significativo, ao nível de $2 \%$ de probabilidade ( $P<0,0.1$ )。

0 teste $t$, de "Student", alicado aos dados re ferentes ao peso de frutos de abacaxizeiro (Tabela 9), em função de diferentes pewos de mudas, jlantadas na época chu vosa, mostrou que os jesos de mudas influenciaram sirnifica tivamente $(I<0,01)$ os pesos dos frutos. 
IVa Figura 1 pode-se observar que o peso maximo dos frutos obtidos na época chuvosa foi de $2599 \mathrm{~g}(2,60 \mathrm{~kg})$, para peso de muda de $447 \mathrm{~g}$. O coeficiente de determinação corrifido $\vec{r}^{2}=85,97 \%$, mostra que $85,97 \%$ da variaçąo nos pe sos dos frutos são explicados pelos pesos das mudas, num modelo do segundo grau, com uma variável independente.

\subsubsection{Plantio da época seca}

Tabela 10 - Coeficientes de regressão estimados $\left(\hat{b}_{i}\right)$, des viosmpadxão desses coeficientes $s\left(b_{i}\right)$; valores de $t$, de "Student", e coeficientes de determing ção $\left(r^{2}\right.$ e $\left.\vec{r}^{2}\right)$, para pesos de frutos de abacaxj zeiro, em função de diferentes pesos de muảas, plantadas na éroca seca

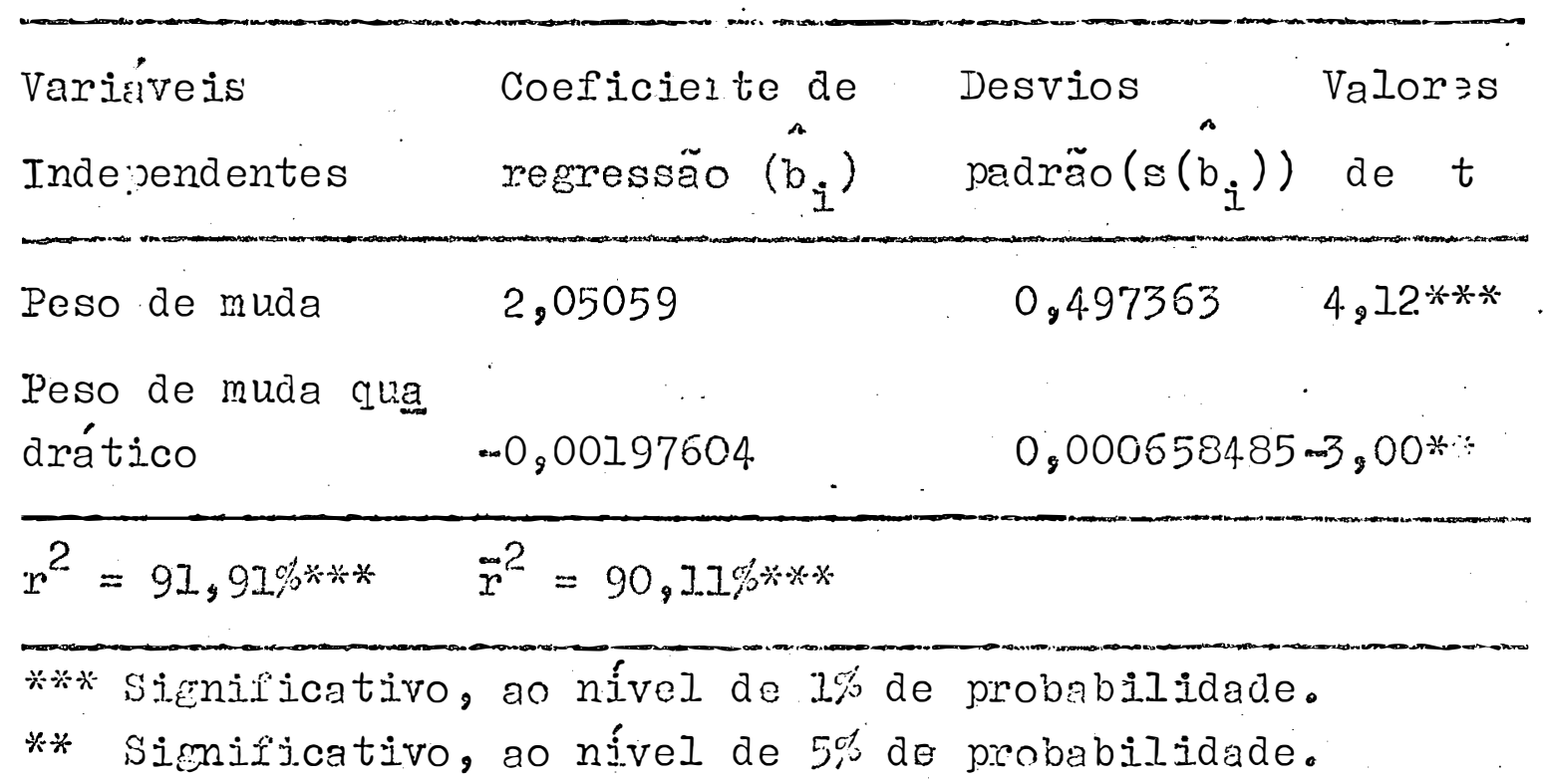




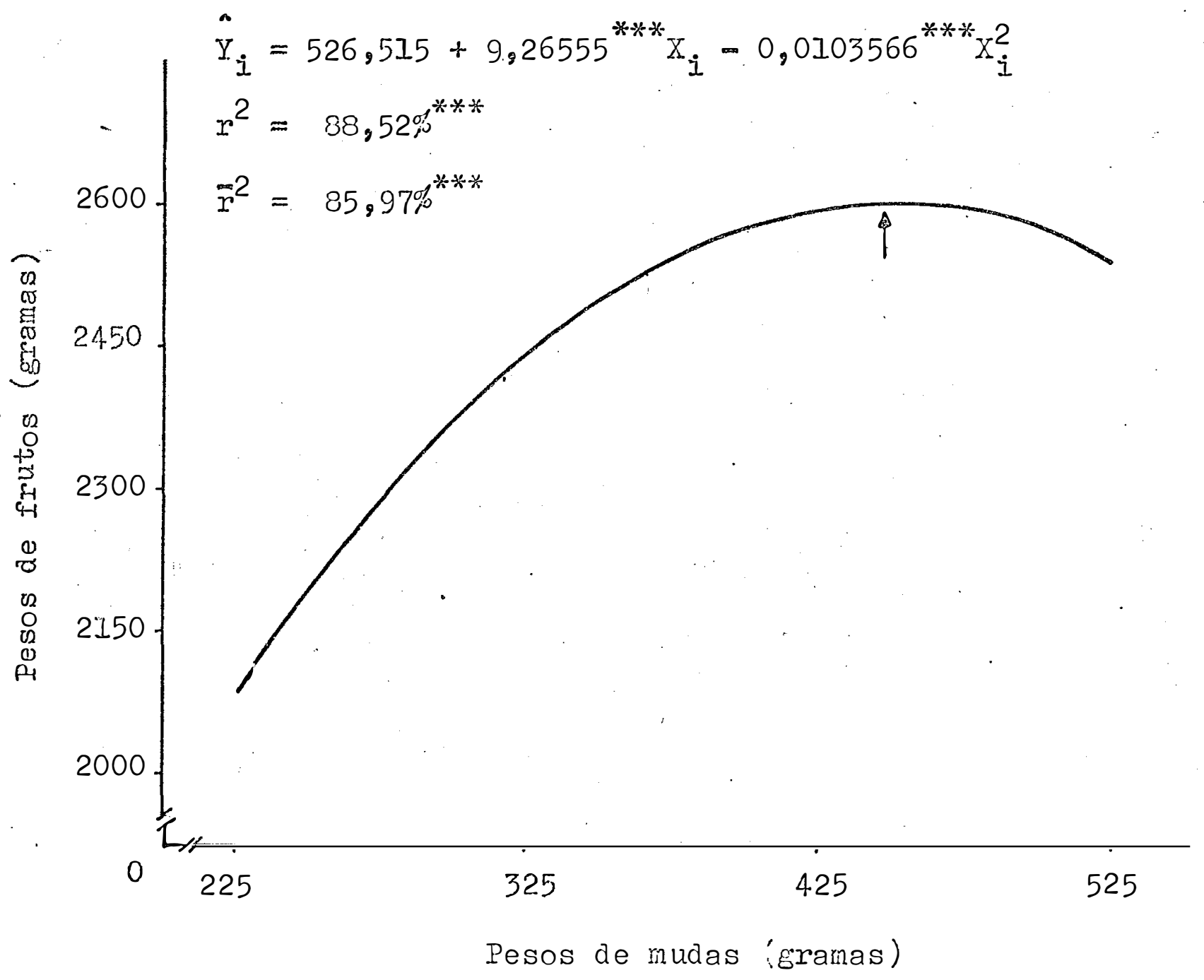

Ijjerura 1. Pesos de frutos de abacaxizeiro $\left(\hat{Y}_{j}\right)$, em funç̃o de diferentes pesos de mudas $\left(X_{i}\right)$, plantadas na época chuvosa. O peso máximo de $2599 \mathrm{~g}$, apontado pela seta, corresponde ao peso de mude de 4.47 \& ${ }^{* * *}$ sis nificativo, ao rifvel de $7 \%$ de probabilidade). 
0 teste $t$, do "Student", aplicado aos dacos re ferentes ao peso de frutos de abacaxjzeiro (liabela 10), em runção de diferentes pesos de mudas, plantadas na época se ca, mostrou que os pesos de mudas influenciaram sifnificati vamente $(P<0,01)$ e $(P<0,05)$ os pesos dos frutos. iTa rigura 2 pode-se observar que o peso náximo dos frutos obtidos na época seca foi de $1703 \mathrm{~g}(1,70 \mathrm{~kg})$, para peso de muảa de 519 \&. O coeficiente de deterninação courigido, $\vec{r}^{2}=90,1.1 \%$, mostra que $90,11 \%$ de variação nos pesos dos frutos são explicados pelos pesos das mudas, num modelo do segundo grau, com uma variável independente.

\subsection{Ifeito de diferentes pesos de mudas, plantadas na época seca, e diferentes teores de nutrientes da fo Iha "D" sobre o peso médjo dos frutos}

5.6.1. Heito de difirentes pesos de mudas e diferen tes teores de $\mathbb{N}, P$ e $I_{2}$

Os teores de $\mathrm{I}, \mathrm{P}$ e $\mathrm{K}$ na folha "D" não influen ciaram simificativamente, nos níveis preestabelecioos, o peso nédio dos frutos. 


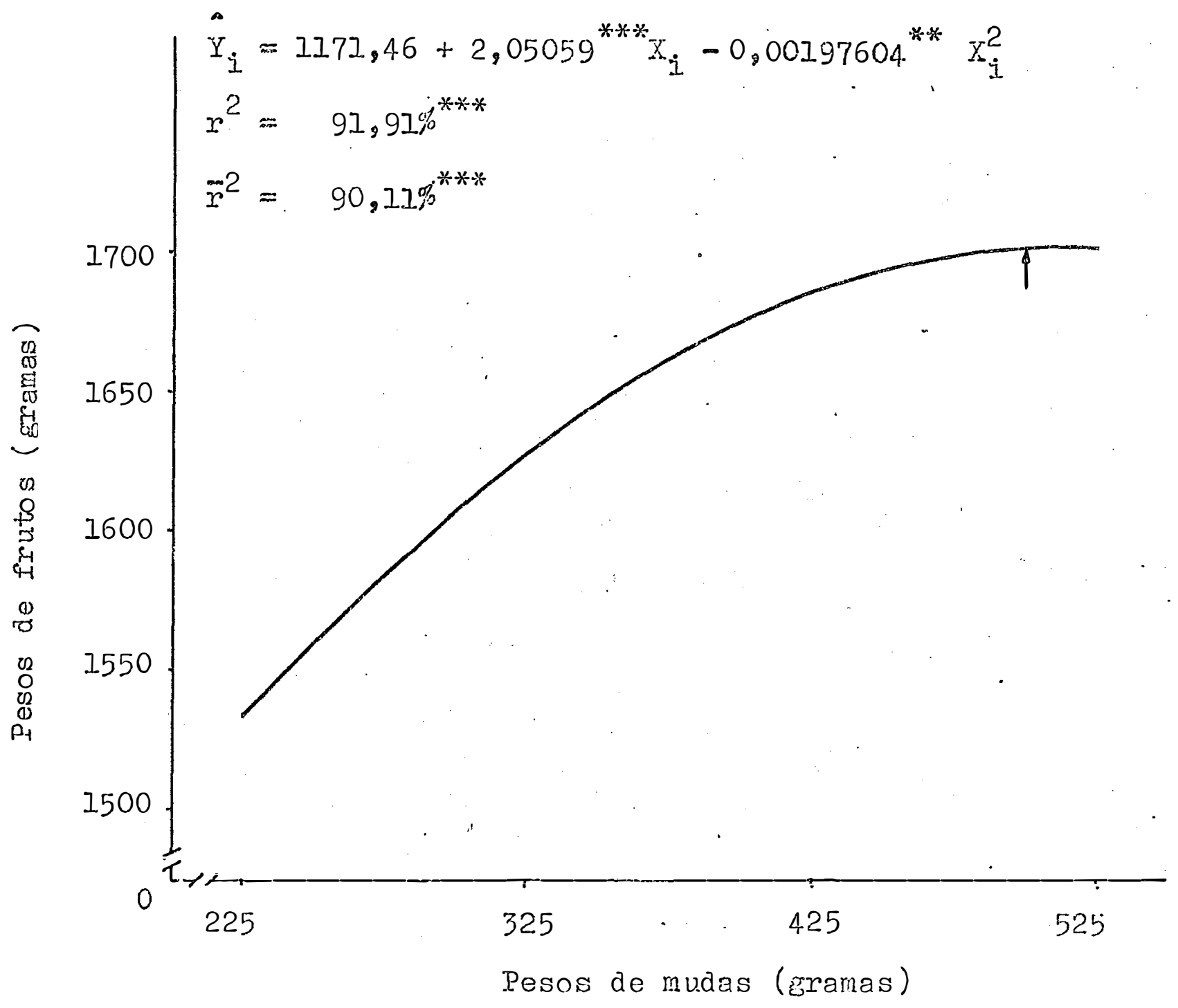

Ficura 2. Pesos de frutos de abacaxizeiro $\left(\hat{Y}_{j}\right)$, em função de di ferentes pesos de mudas $\left(X_{i}\right)$, plantadas na época seca. o peso máximo de 1703 g̈, apontado pela seta, corresckin de 90 peso de muda de $519 \mathrm{E}$ (*** e ** significativos, aos níveis de $2 \%$ e $5 \%$ de rrobabilidade, respectivamen te). 
5.6.2. Hifeito de difexentes pesos de mudas e diferer tes teores de $\mathrm{Ca}$

Tabela 11 - Coeficientes de regressão estinados $\left(\hat{b}_{\dot{i}}\right)$, desvi os-padrão desses coeficientes $\mathrm{s}\left(\hat{b}_{\dot{j}}\right)$, valores de $t$, de "Student", e coeficientes de àeterminação $\left(R^{2}, \bar{R}^{2}\right)$, para pesos de frutos de abacaxizeiro, em função de diferentes pesos de mudas, plantadas na época seca, e diferentes teores de $\mathrm{Ca}$ na folha "D"

\begin{tabular}{|c|c|c|}
\hline $\begin{array}{l}\text { Variáveis } \\
\text { Inde pendentes }\end{array}$ & $\begin{array}{l}\text { Coeficientes de } \\
\text { regressão }\left(\hat{b}_{i}\right)\end{array}$ & $\begin{array}{l}\text { Desvioš- } \quad \text { Valores } \\
\text { padrão }\left(\hat{s}\left(\hat{b}_{i}\right)\right) \text { de } t\end{array}$ \\
\hline Peso de mida & 0,489935 & 0,0758722 \\
\hline Teor de Ya & $1,00385 \times 1.0^{3}$ & $4,53626 \times 10^{2}: 2,21 *$ \\
\hline$R^{2}=89,11 \%^{* * * *}$ & $\overrightarrow{\mathrm{R}}^{2}=37,18 \% * * *$ & \\
\hline
\end{tabular}

0 teste $t$, de "Student", aplicado aos dados re ferentes a pesos de frutos de abacaxizeiro (Tabela l.1), en função de diferentes pesos de mudas e diferentes teores de $C_{a}$ da follha "D", mostrou que esses fatores influenciaram sig nificativanente $(P<0,01)$ e $(P<0,10)$ os pesos médios dos frutos. 
Na ligura 3 pode-se observar que o maior peso dos frutos das mudas plantadas na época seca foi de $1711 \mathrm{~g}$ $(1,70 \mathrm{~kg})$, para peso de muda de $525 \mathrm{~g}$ e teor médjo de Ca de $0,2293 \%$. o coeficiente de determinação corrigido, $\overrightarrow{\mathrm{R}}^{2}=87,38 \%$, mostra que $87,18 \%$ de variação nos pesos dos frutos são ex plicados pelos pesos das mudas e pelos tecres de Ca, num mo delo do primeiro grau, com duas variáveis independentes.

5.6.3. Wfeito de diferentes pesos de mudas e diferen tes teores de $\mathrm{Mg}$

Tabela 12 - Coeficientes de regressão estimados $\left(\hat{b}_{j}\right)$, des vios-padrão desses coeficientes $s\left(\hat{b}_{i}\right)$, valores de $t$, de "Student", e coeficjentes de determing ção $\left(R^{2}\right.$ e $\left.\overline{\mathbb{R}}^{2}\right)$, para pesos de frutos de abacaxim zeiro, em função je diferentes pesos de rudas. plantadas na épcci seca, e diferentes teores de vig na folna "j"

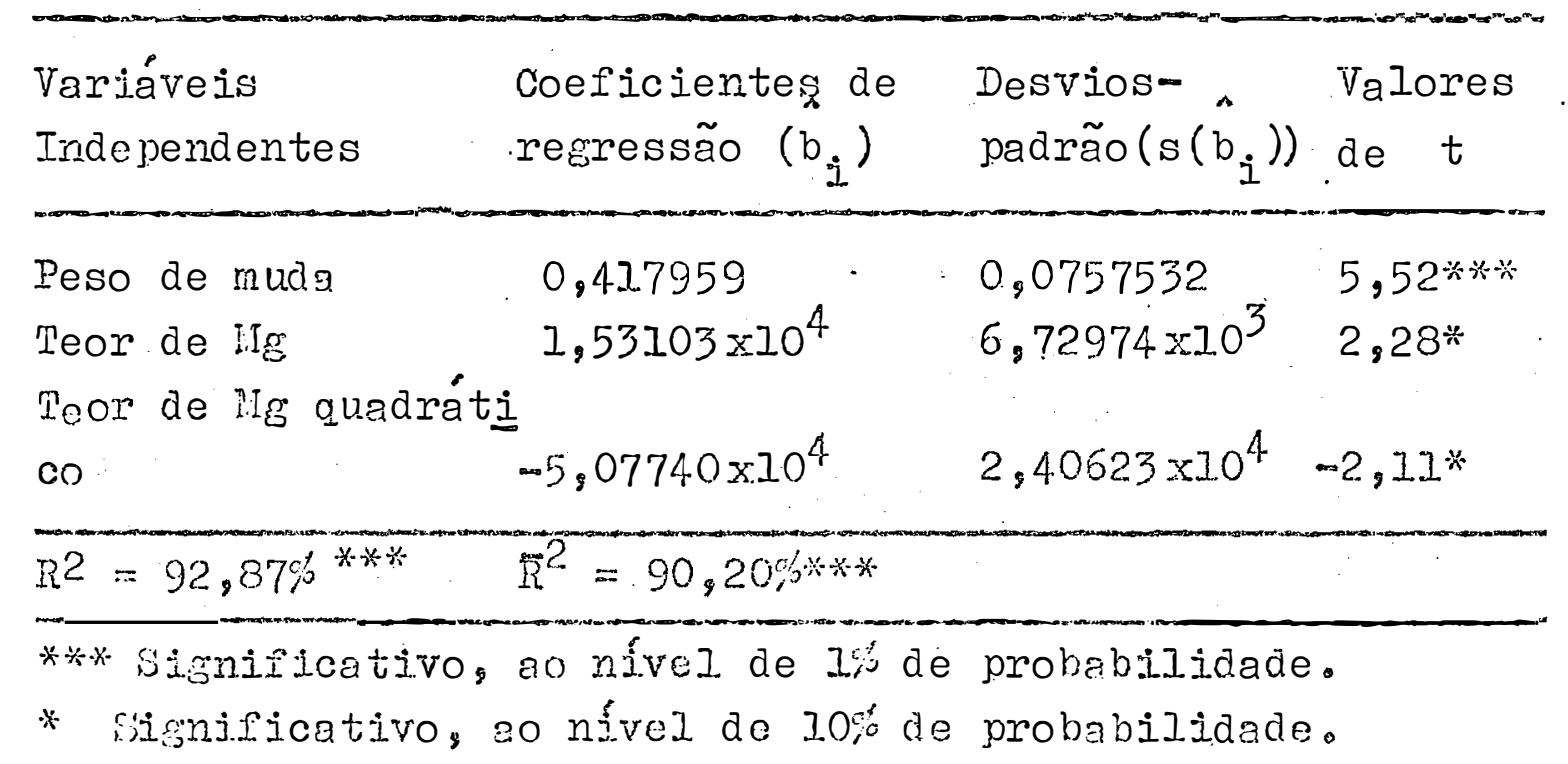




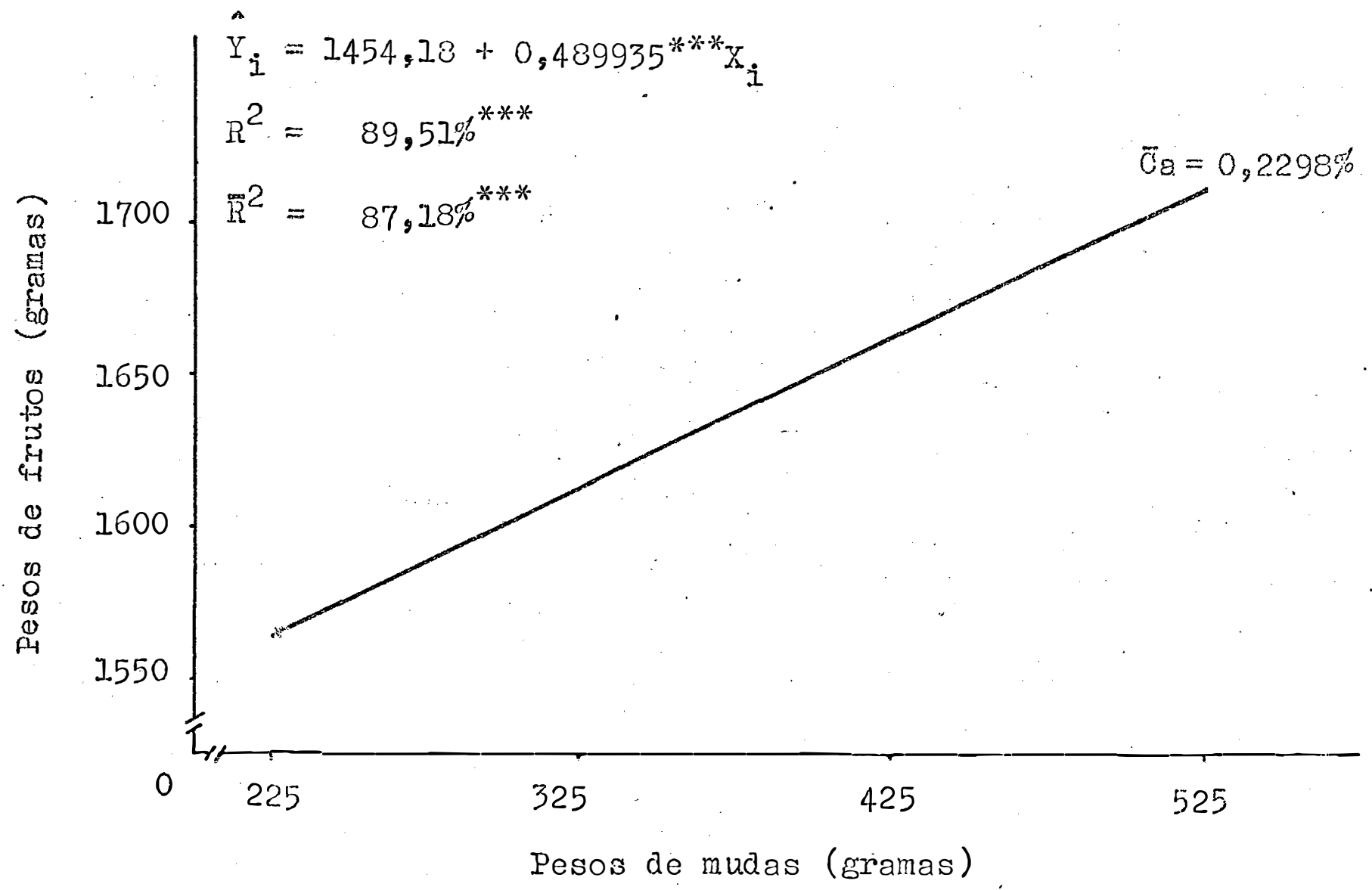

Fjoura 3. Pesos de frutos de abacaxizejro $\left(\hat{Y}_{1}\right)$, em funçäo de dife rentes pesos de mudas $\left(X_{i}\right)$, plantadas na época seca, e do teor de cálcio da folha "D", onde Ca $=0,2298 \%$ éa mé zìra ae teores de cálcio. O maior peso de fruto obtido,

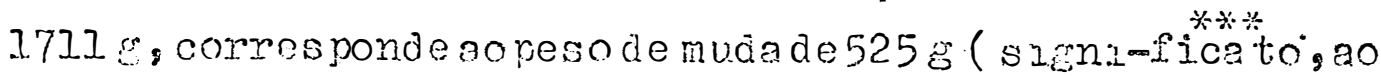
nivel de $1 \%$ de pro babiljdade) 
O teste $t$, de "Student", aplicado aos ảados re ferentes a pesos de frutos de abacaxizeiro ( $\mathrm{l}$ abela 1 ), em função de diferentes pesos de mudas e diferentes teores de $\pi$ da folha "D", mostrou que esses dois fatores influencia ram significativamente $(P<0,01)$ e $(P<0, I 0)$ os pesos né dios dos frutos.

lia Figura 4, pode-se observar que o maior peso dos frutos obtidos das mudas plantadas na época seca foi de $1,712 \mathrm{~g}(1,70 \mathrm{~kg})$, para peso de muda de $525 \mathrm{~g}$ e teor médio de $\mathrm{IIg}$ de $0,1341 \%$ o coeficiente de determinação corrigido, $\bar{R}^{2}=90,20 \%$, mostrou que $90,2 \dot{0} \%$ da variação nos pesos dos frutos são explicados pelos pesos das mudas e pelos teores de $\mathrm{Ig}_{\mathrm{g}}$, num modelo do segundo grau incompleto, com duas var áveis independentes. 


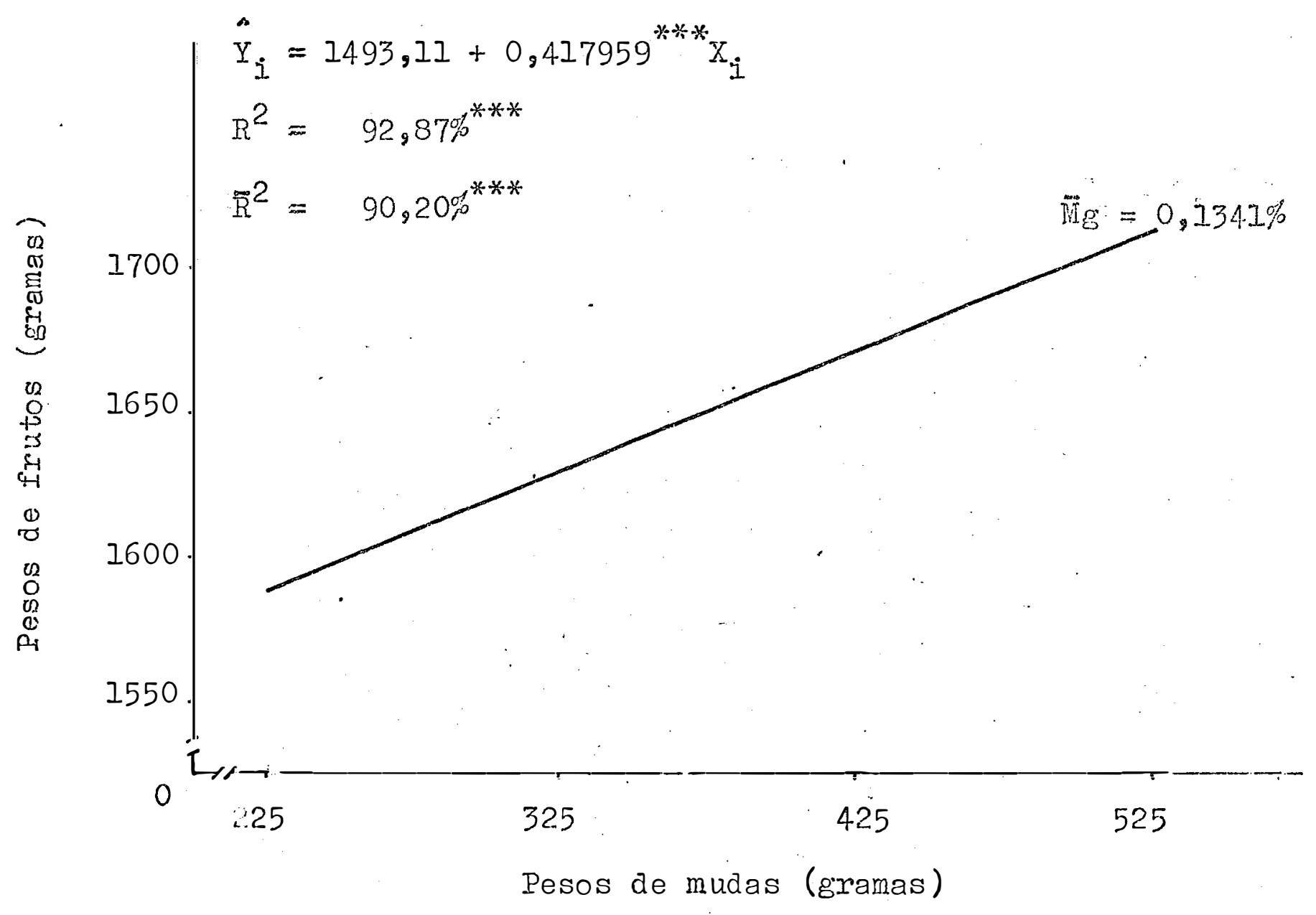

Figura 4. Pesos de frutos de abacaxizeiro ( $\left.\hat{Y}_{i}\right)$, em função de di ferentes pesos de mudas $\left(X_{i}\right)$, plantadas na época seca, e do teor de magnésio da folha "D", onde $\mathbb{R}_{\xi}=0,1341 \%$ é a média dos teores de magnésio. o maior peso de fruto obtido, 1712 g, corresponde ao peso de muda de 525 \& (*** Significativo, so nível de $1 \%$ de probabilidade). 
5.6.4 3iteito de diferentes pesos de mudas e diferen tes teores de $\mathrm{S}$

Tabela 13 - Coeficientes de regressão estinados $\left(\hat{b}_{i}\right)$, des vios-padrão desses coeficientes $\mathrm{s}\left(\hat{\mathrm{b}}_{\dot{i}}\right)$, valores de $t$, de "Student", e coefjcientes de determina ção $\left(R^{2}\right.$ e. $\left.\tilde{R}^{2}\right)$, para pesos de fruto de abacaxi zeiro, em função de diferentes pesos de mudas, plantados na época seca, e diferentes teores de S na follha "D"

Variáveis

Coeficientes de Desviosm

Valores

Independentes regressão $\left(\hat{b}_{i}\right)$ padrão $\left(s\left(\hat{b}_{i}\right)\right)$ de $t$

Peso de muda

1,73938

$0,42924.6$

$4,05 \% * \%$

Tecr de $\mathrm{S}$ - $1,72628 \times 10^{3}$ $7,43906 \times 10^{2}$ $2,32 * * *$

Peso de muda qliadrá tica $-0,0016738.7$ $0,00055534-3,01 * *$ $R^{2}=95,16 \% * * \quad R^{-2}=93,34,5 \% *$ **K Sicnificativo, ao nível de $1 \%$ de probabilidade. ** Sicnificativo, ao nível de $5 \%$ de probabilidade.

O teste t, de "Student", aplicado aos dados re ferentes a pesos de frutos de abacaxizeiro (rabela 13), em funç̃o dos ajiferentes pesos de mudas o diferentes teores de $S$ da rolha "D", mostrou que essos dois fatores influenciam 
ram simificativamente $(P<0,0 I)$ e $(P<0,05)$ os pesos mé dios dos frutos.

Ta Tizura 5 pode-se observar que o peso máxino dos frutos obtidos das mudas plantadas na época seca ioi de I.694 $\mathrm{g}\left(\mathrm{I}_{\mathrm{g}}\right.$. lig $)$, para peso de muda de $520 \mathrm{~g}$ e teor médio de $S$ de $0,1244 \%$ coeficiente de determinação corriçido, $\vec{R}^{2}=93.34 \%$, mostrou que $93,34 \%$ da variação nos pesos dos frutos são explicados pelos pesos das mudas e pelos teorea de $S$, num modelo do segundo grat incompleto, com duas variá veis independentes.

5.7. Efejto de diferentes pesos de mudas e épocas de plantio scbre o peso médio dos erutos

A análise de variância dos daỏos de peso médio dos frutos do abacaxizeiro, em fuiç̧ão de diferentes pesos de mudas, plantadas nas épocas chivosas e seca (Tabe la 14), mostrou que os efeitos das érocas e pesos de mudas sobre o peso médio dos frutos foram estatísticamente diferentes ( $P<$ $0,01)$.

Ta Higura 6 pode-se observar que o peso mécio má ximo dos frutos obtidos de diferentes pesos de mudas, na época chuvosa, foi de $2,599 \mathrm{~g}(2,6 \mathrm{~kg})$, para peso de muda de $4.47 \mathrm{~g}$, ao passo que para o plantio efetuado na época seca foi de $1,703^{\circ} \mathrm{E}(1,73 \mathrm{~kg})$, para peso de muda de $519 \mathrm{E} \cdot$ 


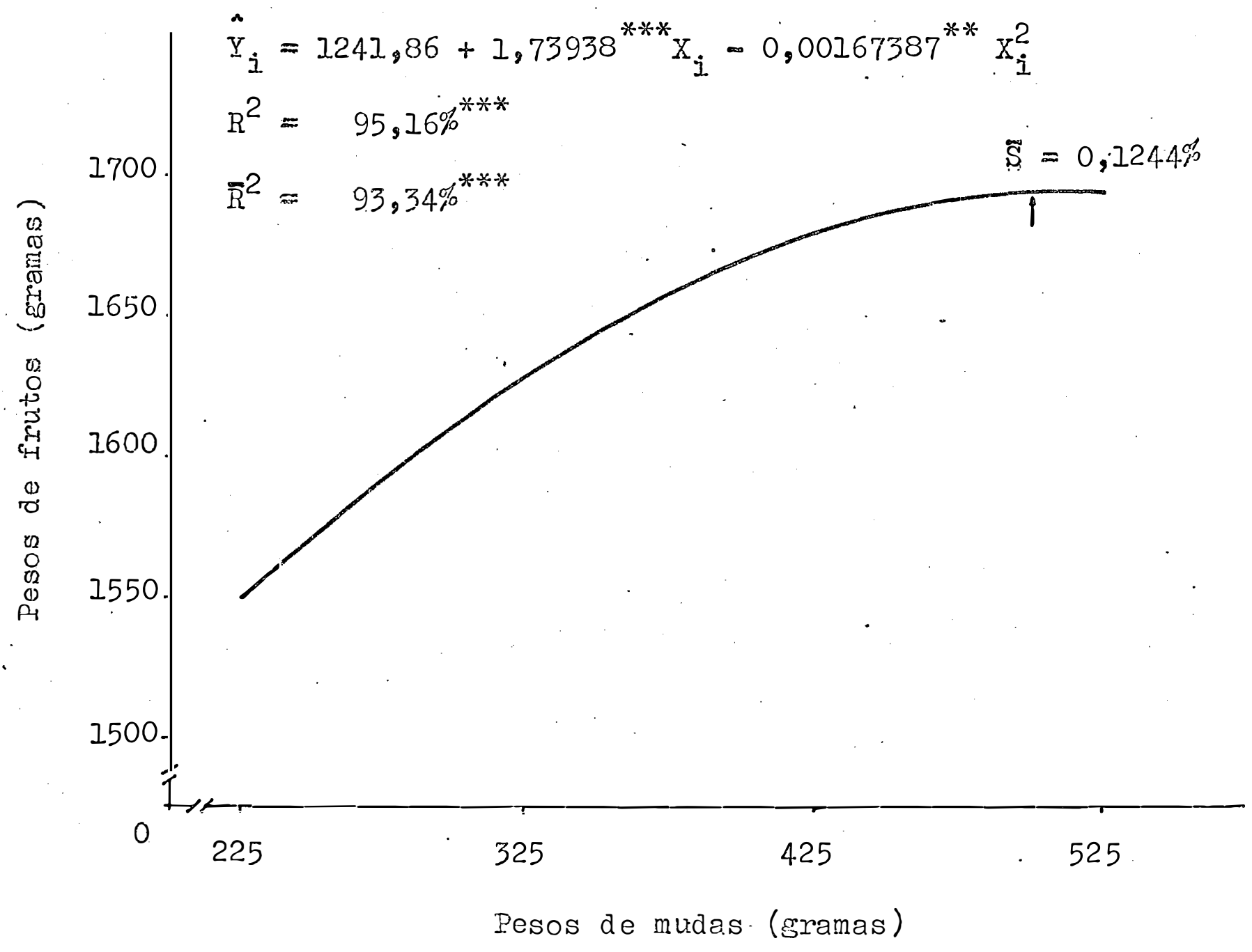

Figura 5. Pesos de frutos de abacaxizeiro ( $\left.\ddot{Y}_{i}\right)$, em função de dí ferentes pesos de mudas $\left(X_{i}\right)$, plantadas na época seca, e do teor de enxoire da fotha "D", onde $\$=0,1244 \%$ é a médja dos teores de evixolre. 0 peso máximo de 1694 E, apontado pela seta, corresponde ao peso de muda de 520 g (*** e ** significativos, ao níveis de $1 \%$ e $5 \%$ de probabilidade, respectivamente). 


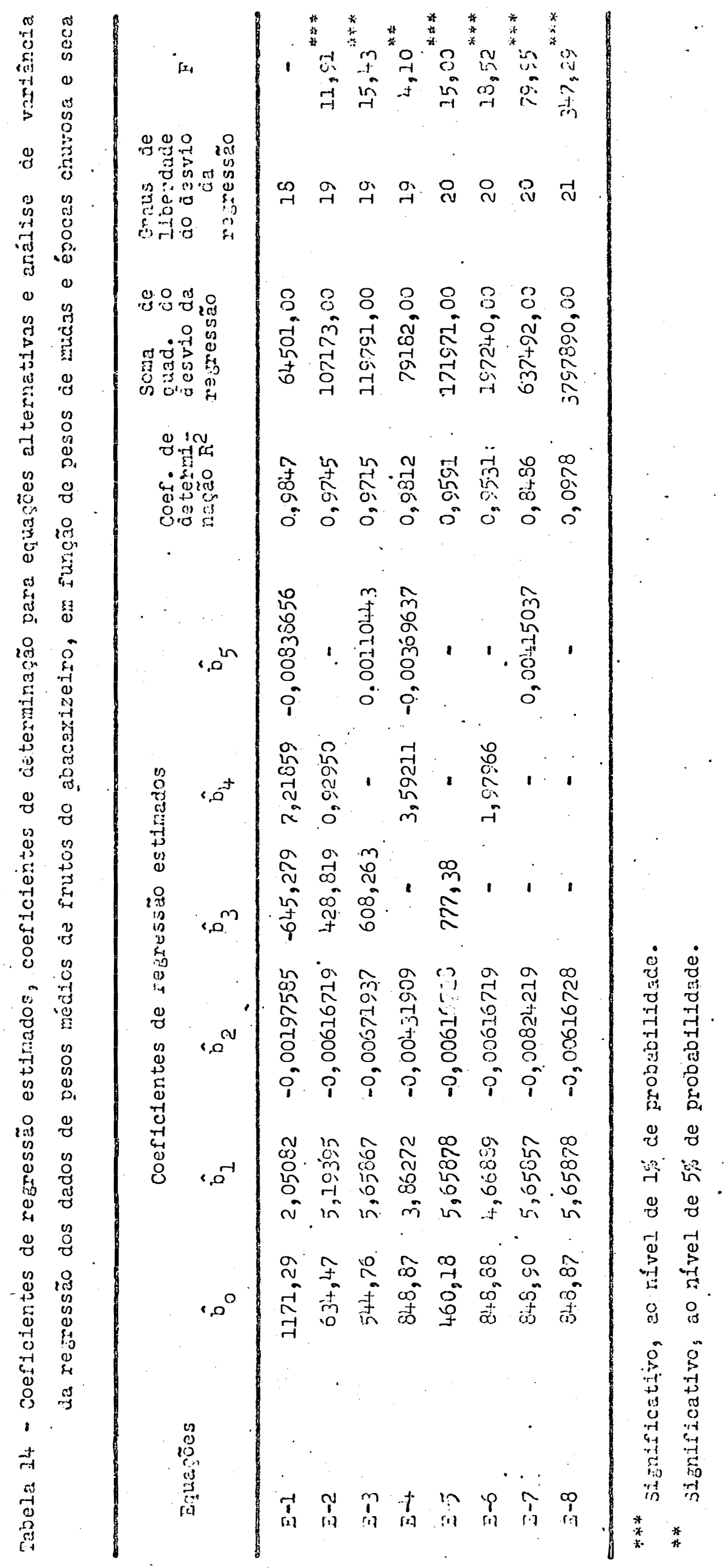




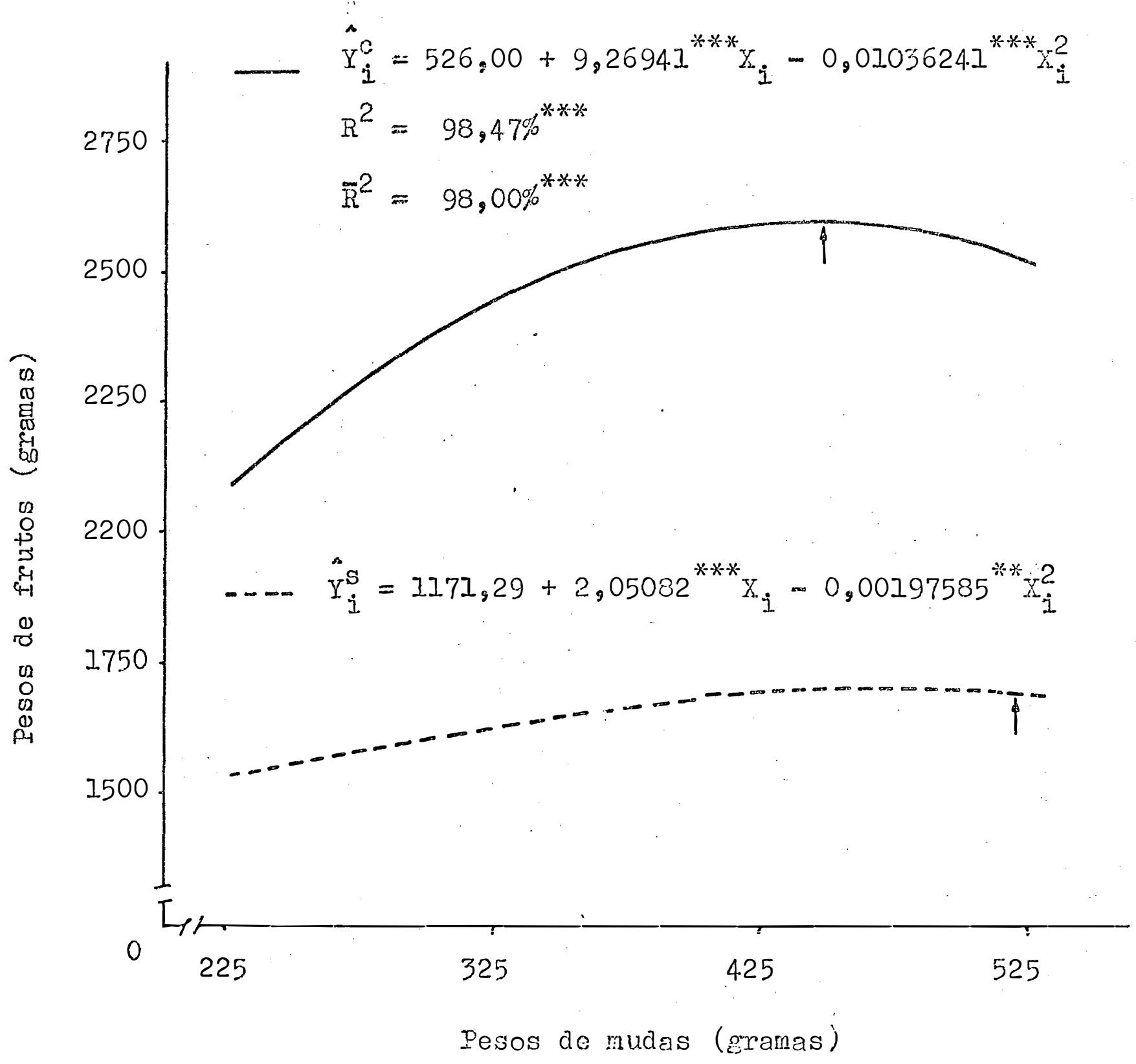

Figura 6. Pesos de frutos de abacaxjzeiro $\left(\hat{Y}_{i}^{C}\right.$ e $\left.\hat{Y}_{i}^{S}\right)$, em função de diferentes pesos de mudas $\left(\mathrm{X}_{\mathrm{i}}\right)$, plantadas nas épocas chuvosa e seca, respectivamente. Os pesos máxi mos àe 2599 e 1703 \&; apontados pelas setas, corres pondem ans pesos de mudas de $4.47 \mathrm{~g}$, para época chuvosa, e 519 E⿱ sos níveis de $2 \%$ e $5 \%$ de probabilidade, respectivamen te). 


\section{I. Brix médio dos frutos}

De acordo com a análise de variância dos dados de brix médio ỏos frutos (Tabela 3), o valor de ir foi signi ficativo, ao nível de $I$ fr de probabilidade $(P<0,01)$, para épocas de colheita. A comparação das médias dos dados de brir, entre os meses de critheitas, pelo teste de Tukey (Ta belä 4), mostrou que os vazores de brix dos frutos ccinjidos nois meses de janeiro, fevereiro, dezembro e junho nãc se di ferenciaram entre si estatisticamente $(P<0,01$.$) . Cs valo$ res de brix dos frutos colridos em janeiro e fevereiro fo ram estatisticamente diferentes $(P<0,0.1)$, dos valores de brix dos frutos colnidos nos meses de julho a ąosto. Notase que o brix dos frutos colhidos em agosto e julho não di fere, estatisticamente, $(R<0,01)$, do brix dos frutos $c o$ Inidos em dezembro e junho.

observou-se un aumento considerável do brix dos 
frutos colnjoos nos meses mais quentes (dezembro, janeiro e fevereiro), de 16,33 a $17,00 \%$, e um decréscino, de 13,83 a 13,17\%, nos colhicios nos neses mais frios (junhos juIho e agos to).

Esisa tendëncia de brix concorda com a observada por FAAG et alii (1963), com a variedade de abacaxi 'Pérola', por DULI (I971), IANTDIER e PY (1971), GAILIARD (1969), PY, citado por GIACONEIII (1977), GIACONELII (1977) e GIACONIEIJI et aljij (1979), que utilizaram a variedade 'Smooth Cayenne', obtendo brix médio dos frutos entre 13,96 e 16,4\%. Houve divergencia entre os resultados obtidos por ROINTHRGP(I964), com a veriedade 'Pérola', e os de WEe (1969) e Hirang (1958), que obtiveram brix médio dos frutos entre 10,9 e $12,6 \%$

GIACORIII et alij (1979) concluíram que os va Icres máximos de brix foram obtides quando a maturaçăo dos frutos se deu em época quente e úrida, o que está de acordo com os resultados do presente trabalho, em que os valores de brix mais elevados foram obtidos nos frutos colhicios na época de chuva e no verão (dezembro, janeiro e fevereiro). A concordância ou discordäncia dos resultados é explicada por COLIJITS (1968), STHGJTION e GORTIPR (1965), SCARBIERI (1966), STINO (1971), SOUZA Jr。 (1972) e TRTA (1977) coro sendo resultado da influencia das condições de. ambiente, cono umidade, temperatura, altitude, etc., que influenciam os ceracteres dos fintos nas diforentes regj ões e épocas de colhejta. 


\subsection{Acidez médja titulável dos frutos}

De acordo com a análise de varianncia dos dados de acidez média dos frutos (Tabela 5), o valor de F foi sig nificativo ( $P<0,01$ ) para épocas de colheita. A compara ção das médias dos dados de acidez, entre os meses de co Iheita, pelo teste de tukey (Tabela 6), mostrou que a acidez média dos frutos colnidos em julho, agosto e junho foi esta tisticamente diferente $(P<O, O I)$ da acidez média dos colni dos em fevereiro, janeiro e dezembro.

Observou-se un aunento consiảerável da acidez dos frutos colhidos nos meses mais frios (junho, julho e agosto) e um grande declínio naqueles colnidos nos meses mais quentes (dezembro, janeiro e fevereiro).

A acider média, que viariou de 6,00 a $6,43 \%$, para a colheita dos meses de dezembro, janeiro e feveriro, é seme thante à acidez média de $7.2 \%$, obtiáa por GIACONEIII. (1972), em Bebedouro, e porGAIIIART (I969), em Cameron。

De acordo corn PY, citado por GIACONTLII (19'77), o mercado externo e a indústria preferen frutos menos doces, ao passo que o mercado brasileiro dá preferência a frutos mais doces.

Os frutos colhidos nos meses fries do inverno (junho, jultho e axosto) apresentiaram acidez rédia de 15,93 a 20,10\%, acjdez essa não concordante com as obtidas por

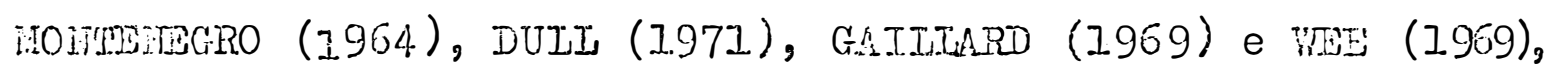


mas que é explicada por COIIJTS (1968), HATIDIER e PY(1971) e HUIT (1958), segundo os quais a acidez total é influencia da essencialmente pela temperatura na época de maturação dos frutos e que os frutos colnidos em condições de temperatum ras baixas apresentam baixo conteúdo de açúcares e acidez elevada. Hos meses mais frios do ano, na região onde se conduziu o presente trabaiho, a temperatura mínima foi de $16,3^{\circ} \mathrm{C}$ e a máxima de $29,2^{\circ} \mathrm{C}$, ocorriảa nos meses mais quen tes do ano, com temperatura média anual de $21,7^{\circ} \mathrm{C}$, considerando dados de 29 anos. Esse aspecto serve para explicar por que os frutos colhidos no inverno apresentaram elevada acider média, quando comparados com os frutos colnidos no verão, na mesma área experimental.

\subsection{Relação média brixiacidez dos frutos}

De acordo com a anälise de variância dos dados relativos à relação média brix/acidez dos frutos (Tahela 7), o valor de $\mathrm{P}$ foi significativo $(\mathrm{P}<0,01)$ para épocas de $\mathrm{co}$ Iheita. A comparação das mécias àa relação brix/acidez doss frutos, entre os meses de collheita, peló teste de rukey (ila. bela 8), mostrou que os frutos colnjoos em dezembro, janei. ro e fevereiro foram estatisticamente diferentes $(P<0,01)$ dos colhidos en junho, juIho e agosto.

Observou-se um decréscimo da relação brix/acjciez dos frutos colnidos de dezembro a agosto, sendo que as dife 
remgas foram majores quando as colkeitas dos meses mais quentes (dezemoro, janeiro, fevereiro) foram separadas das colheitas dos meses mais frios (junho, julho, agosto), na região em que se conduriu o trabalho.

GAIIIA.RD (1969) encontrou, colhencio frutos em diferentes épocas e condições, em Cameron, relação brix/ac i. dez de 0,99 a 1,66, resultado superior ao obtido neste tra balho, em que os frutos colhidos nos meses frios apresenta ram relação média brix/acidez de 0,79 . A colneita efetua da nos meses quentes já apresentou relação média brixáacidez bem mais elevada, 2,39.

De a.cordo com HASNDIER e PY (1971), HUET (1958) e GIACONIEIJI. (1977), é desejável que a acidez dos frutos que se destinarn à indústria e ao mercado externo currespoñ da a mais de 9 e ménos de 15 milijitros de soda 0, lo por 10 wijilitros de suco e que a relaçác brix/acidez estej : próx.i ma de 1,2, bem mais baixa que a média dos frutos colnidos nos meses quentes $(2,39)$ e um pouco mais elevada que a dos colhidos nos meses mais frios $(0,79)$.

Os resultados obtidos por GLACORELII (1972), em Bebedouro, o qual encontrou relação brix/acidez de 2,3 para os frutos colhidos en janeiro e fevereiro são bem coinciden tes com os resultados obtidos neste trabalho: reiação média brix/acider de 2,39, para os frutos colhidos nos meses quen tes (verão), dezembro, jareiro, fevereiro.

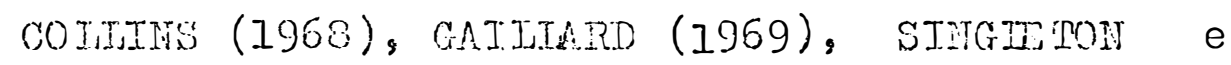


GORTIER (1965), SGARBIERI (1.966), SIMÃO (1971), SOUZA Jr。 (1972) e IRPA (1977) concluíram que as condicões de mibiente (unidade, temperatura, insolação, altitude, etc.) podern in fluenciar profundamente as características dos frutos na co Iheita, o que explica os resultados referentes a brix, aci dez e relação brix/acidez no presente trabalio, consideran do as características climáticas da região.

Os Índices qualitativos apresentados por COSTA (1979) para o mercado interno brasileiro e para o cultivar 'Smooth Cayenne', brix de 16,0 a $19,0^{\circ}$, aciaez de 7,0 a $12 \%$ e relação brix/acidez de 1,3 a 2,7 , estão próximos dos $0 \underline{b}$ tidos neste trabalho.

6.4. Efeito de espacarnentos sobre o peso médjo dos frutos

$D_{e}$ acordo com os resultados obtidos neste traba Iho, os espaçamentos estudados, com densjdades de $294: 11$ a 33333 plantas por hectare, não influenciaram signifisativa mente, ros níveis preestabelecidos, o peso médio dos frutos. Esse fato ocorreu não só para o plantio efetuado na época chuvosa, cono tarnoém para o plaztio da época seca.

0 aumento de 3922 plantas por hectare, obtido do maior espaçamento $(120 \times 50 \times 40 \mathrm{~cm}$ ) para o menor ( $120 \times$ $30 \times 40 \mathrm{~cm}$ ), proporcionou, na coineita, maior número de fru tos con peso médio de $I_{8} 98$ a $2,60 \mathrm{~kg}$ (com a coroa), no plan tio efetuado na época churosa, e de 1,51 a I,72 kg (com a 
coroa), no plantio da época seca. Msses pesos médios não foram influenciados significativamente, nos níveis preestabelecidos pelos espaçamentos estudados e estão dentro dos pesos médios desejáveis, não só para a industrialização, na forma de rodelas $(1,50$ a $2,00 \mathrm{~kg})$, como também para a expor tação ao natural $(1,30$ a $1,50 \mathrm{~kg})$, concordando com os resul tados obtidos por GIACONIII (1972), em Bebedouro, com a va riedade 'Smooth Cayenne', e con as recomendações de PY e TISSERU (I.965).

YO SII IARA E HWAIIG (1957), CARDTMTALII $(1966,1966 \mathrm{a}$ e 1969), WEB (1969), TRTO et alii (1974), em trabalhos eX perimentais realizados em diversas regiões do Brasil e do mundo, utilizando diferentes variedades, confirmam que um aumento de densidades de plantas de 5 a 20 mil plantis por hectare pode ocasionar pequenas iferencas entre pescs mé dios dos frutos, sendo que, na majuria das vezes, ess zs diferenças não são significatives, embora os rendimentos por hectare sejam altamente significativos.

Segundo JAIITCK (1966), o a umento da populaş̃ó de plantas numa mesma área influencia o desenvolvinento dos indivíauos, dejois de atingido determinado ponto, em que ca da planta passa a competir pox fatores de crescinento como Iuz, água e nutrientes, o que não chegou a acontecer com as densidades de plantios usadas no presente trabaliho e com olu tras densidades u.tiljzadas nos trabalihos cita 
6.5. Wifejto de diferentes pesos de mudas sobre o peso mé dio dos frutos.

C teste de to de "Student", aplicacio aos dados referentes a pesos de frutos de abacaxizeiro, em função de diferentes pesos de mudas, plantadas em épocas chuvosa e se ca. (Tabelas 9 e 10), mostrou que os pesos de mudas influen cjaram signjficativamente $(P<0,01)$ os pesos dos frutos do plantio da época churosa e do plantio da época seca $(P<O, O I)$ e $(P<0,05)$.

Os pesos médios dos frutos do plantio da época chuvosa foram de $1,98 \mathrm{~kg}$, para as mudas com pesos médios de $225 \mathrm{~g}$, até $2,60 \mathrm{~kg}$, para as mudas com $525 \mathrm{~g}$. Na Figura I poda-se observar que o peso máximo do fruto obtido ria co Iheita da época churosa foi de $2599 \mathrm{~g}(2,6 \mathrm{~kg})$, par l peso médio do muda de $447 \mathrm{~g}$.

0 peso médio dos :rrutos na colneita do plantio da época seca foi de $1,50 \mathrm{k}$, para mudas com pesos médios de $225 \mathrm{k}$, indo até $1,72 \mathrm{~kg}$ para mudas de $525 \mathrm{~g}$. Ila Ii igura 2 pode-se observar que o peso máximo do fruto obtido na época seca foi de $7703 \mathrm{~g}(1,7 \mathrm{~kg})$, para poso de muảa de $519 \mathrm{~g}$ 。 observou-se, tanto na época chuvosa, em que o $\bar{x}^{2}=85,97 \%$ (Tisura I), como na época seca, $\bar{r}^{2}=90,11 \%$ (Fi Eura 2), que a variação nos pesos dos irutos é explicada pe Ios pesos das mudas, o que está de acordo com os resultados

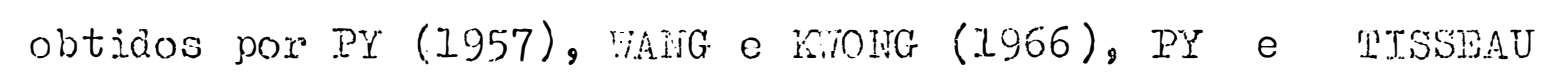


(1965), PY (1964), RTYMEARDT (1968), PY et alij (1968), GAI IIRID (1969), TAY et alii (1976), FORTES e AITDERSTI (1971), GIACORIIII (I972) e YUCHI (1978), que verjuficaram, em traba Thos experimentais efejtos marcantes do uso de diferentes pe sos ou tamanhos de mudas, no plantio, sobre o peso médio dos frutos na colheita. Esses autores trabalharam com a variedade 'Smooth Cayenne' e inúmeras outras, de valor comerciaI no Brasil e em diversas regiões produtoras mundiais. Obtive ram frutios cujos pesos médios variaram de 1,10 a $2,10 \mathrm{~kg}$.

Iissas variaçöes foram causadas pelas diferenças entre variedades, pelos diferentes pesos de mudas e épocas de plantio. As condições climáticas (insolaçãog precipitaç̃o, etc.) influenciaram o desenvolvimento das plantas, principalmente o comprimentc do dia, que é o faton que mais inf:.lui na indução natural ca inflorescência, Vindo em segu da a temperatura, segundo II et alij (1968), GAILIARD(1969), PY '1970) e GIACOLILIII (1972)。

6.6. Ifeito dos teores de nutrientes da folha "I" sobre - peso médio dos erutos

6.6.1. Bfeito dos teores de $\mathbb{N}, P$ e $K$

Was condições deste trabalho os teores de $\mathrm{H}, \mathrm{P}$ e Th na folha "D" hão influenciaram significativamente, nos ní veis preestabelecidos, os pesos médios dos frutos. os teg 
res médios obtidos de $\mathbb{N}(0,93 \%)$, P $(0,085 \%)$ e $K^{\prime}(2,66 \%)$ es tão próximos dos teores de iv e $K$ encontrados por IUCEI (1978), que realizou trabalho em condições semejhantes, com a varie dade 'Smooth Cayenne', mas o teor de P está bem abaixo.

WEI et a]ii (1969), com a variedade de abacaxi 'Singapore Spanish', não encontraram correlação entre os teores de iv e P na folha "D" e o rendimento da cultura, con firmando os resultados deste trabalho para os teores médios de $\mathbb{N}$ e $P$, mas encontraram correlação positiva em quase to dos os casos, para os teores de $\dot{K}$.

SAMIUIS e DIAZ (1960), citados por SAHUELS et a]ij (1955), obtiveram resultados discordantes para os teores de IN e P; SU (1966), GODIREY - SAM - AGGREY (1970), SA WUIS et a Iji (1955) e PAN (1957) encontraram resultados discordantes para $\mathrm{I}, \mathrm{P}$ e $\mathrm{F}_{2}$.

Neste trabalho, os frutos que a pres mntaram $0,93 \%$ de I', $0,085 \%$ de $P$ e $2,66 \%$ de $K$, em média, na follha "D", aos 12 meses de idade, apresentaram pesos médios de 1,50 a 1,70 $\mathrm{kg}$, dentro dos limites para o consumo dos frutos ao natural ou para a indústria. Seछundo HATHDIDR e PY (1971), frutos com peso eatre 1,3 a $1,8 \mathrm{~kg}$ são maiss saborosos. Iogo, as plantas estavam bem supridas de $\mathrm{H}, P$ e $K$, não sendo esses elementos, nas condições do jresente trabalho, limitantes para a produção de bons frutos. 
6.6.2. Wfeito dos teores de Ca, Me e s

0 Teste $t$, de "Student", aplicado aos dados rem ferentes aos pesos dos frutos de abacaxizeiro, em função de diferentes pesos de mudas e diferentes teores de Ca, ing e $S$ da folha "D", do plantio efetuado na época seca (Tabelas IJ, 12 e 13), mostrou que os pesos de mudas ( $P<0,01)$, assinco mo os teores de Ca e $\mathrm{Mg}(\mathrm{P}<0,10)$ e os teores de $\mathrm{S}(\mathrm{P} 60,05)$, influenciaram significativanente os pesos dos frutos.

Pelas ifiguras 3, 4 e 5, pode-me observar que o maior peso de fruto foi de $1711 \mathrm{~g}(1,70 \mathrm{~kg}$ ), para peso de muda de 525 g e teor méaio de Ca $=0,2298 \%$; peso de fruto de I $712 \mathrm{~g}(1,70 \mathrm{~kg})$, para peso de muda de $525 \mathrm{~g}$ e teor médio de $M g=0,1341 \%$ peso de frut! de $I 694 \mathrm{~g}(1,70 \mathrm{~kg})$, para pe: so i.e muda de $520 \mathrm{~g}$ e teor médio de $S=0,1244$ 范 Os crefi-. cier tes de determinação corrigridus $\left(\widetilde{R}^{2}\right)$ foram: do $\mathrm{Ca}, 87,18 \%$; do $\mathrm{Hg}, 90,20 \%$; e do S, 93,34\%. Essas percentagens mostram quanto a variação nos pesos dos frutos é explicada pelos pe. sos das mudas e pelos teores médios de Ca. Uf e $S$ na foltha "D". Os frutos colnidos de plantias com ós teores médios sl. pracitados correspondem aos pesos médios àos frutos de 1,50 a $1,70 \mathrm{~kg}$, bons para o consumo interno de fruta fresca como também para a industrialização. Nas literaturas consulta das, observa-se a deficiência de estudos con deteminação, por análises foliares do abacaxizeiro, dos teores de Ca, is e S na folina "D", ou tentando qualquer tipo de correlação 
desses teores com o peso do fruto.

IUCHI (1978) foi a única autora que fez análi ses de Ca e $\mathrm{Hg}$, obtendo 0,12 a 0,16\% de $\mathrm{Ca}$ e de 0,12 a 0,11\% de $\mathrm{Ig}$; na colheita, obteve frutos com pesos médios de 1,54 a $1,88 \mathrm{kr}$, próximos dos obtidos neste trabalho. Ienhum pes quisador analisou o S na folha "D", que apresentou maior. $\overline{\mathrm{h}}^{2}=93,34 \%$ quando comparado aos do $\mathrm{Ca}$ e do IIg.

\subsection{Ifeito de épocas de plantio (chuvosa e seca) sobre o peso médio dos frutos}

De acordo com a análise de variância dos dados de peso médio dos frutos do abacazizeiro, em função de dife rentes pesos de mudas, plantłảas nas épocas chuvosa: (novenbro) e seca (abril), com besi nos $F$, as épocas tiverern efe tos estatisticamente diferesites $(\mathbf{P}<0,01)$ sobre o peso mé aio dos frutos (Tabela 14).

Observa-se, na kigura 6 , que o peso máximo dos frutos obtidos do plantio de diferentes pesos de mudas na época chuvosa foi de 2599 grcamas $(2,60 \mathrm{~kg})$, para peso de muda de $447 \mathrm{~g}$, ao passo que, para o plantio eretuacio na épo ca seca, foi de $1703 \mathrm{~g}(., 70 \mathrm{~kg})$, para peso de muàa de 519 g. O desenvolvinento vegetativo das mudas plantadas na época seca e fria foi menor e o ciclo foi a unentado dois ne ses, em relação às plantadas na épcoa chuvosa e quente. 
COLIIHS (1968), PY (1970), FAEIDIPR e PY (1971), PY (1973), e GIACOIIIII (1972), que, em plantios efetuados em diferen tes épocas do ano e em diversas regiões do mundo, com diferentes pesos médios de mudas, de 200 a 700 g, obtiveram, na colheita, frutos com pesos que variaram de 1,20 a $1,80 \mathrm{~kg}$; as mudas plantadas na época seca, independextemente dos seus pesos médios, produziram frutos menores, por causa do menor desenvolvimento das plantas no momento da indução natural das inflorescências. As mudas plantadas na época chuvosa e quente tiveram maior desenvolvimento, redução, no ciclo, de 30 dias e frutos com maiores pesos médios, porque foran induzidas ao florescimento natural, quando apresentavam plar tas mais desenvolvidas (maior número de folhas, maiores reservas e porte) que as plantadas na época seca. 
7. COHCIUSODES

Com base nos estudos realizados e para as condi Gões em que foi conduzido o trabalho, chegoumse às seguin tes conclusões:

1. Na safra, os Irutes do plantio da época seca, colnidos en dezembro, janeiro e fivereiro apresentaran brix do suco (16,7 , satisfatórjo, aci ez $(6,3 \%)$ baixa e rilaçăo brix/acidez $(2,7)$ elevada.

2. Na entressafra, os frutos do plantio da época chuvosa, collidos em jumho, julho e agosto apresentaram brjx do suco $\left(13,4^{\circ}\right)$ abaixo do satisfatórie, acidez $\left(17,7^{\circ}\right)$ elevada e relação brix/acidez $(0,79)$ baixa.

3. Sm nenhuma das duas épocas de plantio os espaçamentos infiluenciaram os pesos médios dos frutos.

4. Tanto no plantio da época churosa como no da 
época seca os pesos das mudas influenclaram o peso dos frum tos, em razão do crescente aunento dos pesos das mudas plan tadas.

5. Os resultados jndicam que, além da grande in fluencia dos pesos de mudas sobre os pesos dos frutos na co Iheita, verificou-se a influẻncia das épocas de plantio.

6. Para os mesmos pesos de mudas utilizados nos plantios das épocas chuvosa e seca, os frutos do plantio da época seca apresentaram pessos médios de 1,51 a $I_{8} 72 \mathrm{~kg}$. Os pesos médios dos frutos do plantio da época chuvosa foram mais altos, de $I_{2}, 98$ a $2,60 \mathrm{~kg}$ 。

7. Os teores de $\mathrm{N}, \mathrm{P}$ e $\mathrm{K}$ da folna "D" não influenciaram os pesos médios dos frutos.

8. Para a média dos teores de Ca de 0,2298\%; o maior peso de fruto obtido, I,71 kg; corresponde ao peso d? muda de $525 \mathrm{~g}$, no plantio.

9. Para a média dos teo:es de Mg de 0,1341\%, o major peso de fruto obtido, $1,71 \mathrm{~kg}$, corresponde ao peso de $525 \mathrm{E}$, no plantio.

10. Para a média dos teores de $S$ de $0,1244 \%$ \% peso máximo de fruto obtido, $1,69 \mathrm{~kg}$, corresponde ao peso de muảa de 520 s, no plantio.

17. A melhor época de plantio foj. o da época se ca. 
8. SUTELARY

This research was conducted at the Brperinent Station at Visconde do Rio Branco, Minas Gerais, a locale within the Zona da lata (Deciduous lorest Region), where climatic conditions are very farorable for the production of pineapple (Ananas comosu.s (I.) Merr.).

The objectives vere to aetermine the responses of the pineapple cultivir 'snooth Cayenne', srown in this region, to the effects of planting season (rainy or dr: sea sons), plant spacing, and different weights of the sligs : and, the relationship between the nutrient levels in the "D" leaves and the average weicht. of the fruits. Deterning tions were also made on the relationships between brix, acj. aity, and brix/acidj.ty ratio with respect to time of has. vest of the fruits.

The experinental design was split-plot ranocm block with 7 replications and 12 plants per plot. we 
80.

plants were set in double rows surrounded by border plants. After 12 months, "D" leaves were collected from the dry sea son planting and analyzed for levels of $\mathrm{N}, \mathrm{P}, \mathrm{K}, \mathrm{Ca}, \mathrm{NI}$ and $\mathrm{S}$.

The fruits from the rainy season planting (20/ II/I972) were harvested between June and August, 1974 (winter); and, those from the dry seeson planting (20/04/1973) were harvested from December, 1974 to Pebruary, 1975 (summer). Average fruit weight was determined as weIl as analy ses of ratios of juice to brix, acitidy, and brix/acidity.

The fruits harvested during the sumer (i॰c。, from the dry season planting), for the external market ano industry, had satisfactory levels of brix of the juice, low acidity, and an elevator brix/acidity. For local consunpo tion, the fruits had a very gcod flavor. Fruits harvested during the vinter (i。e, frol: he rajny season planting), for the external market and industry, were below the satis factony level in brix of the juice, had an elevated acidity, and the brix/acidity relationship was low. Theses fruits we re sour to the local consumer.

In neither of the two planting seasons did sram clng influerce significantly $(P<0,10)$ the average fruit weight. The weight of the s]ips had a significant effect $(p<0,01$ e 0,05$)$ on the increase in fruit weights by ream son of the increased growth of the heavier slips. whe levels of $\mathrm{H}, \mathrm{P}$ and $\mathrm{K}$ in the "D" leaf vere 
not correlated significantly $(\mathrm{P}<0,10)$ with the average fruit weight; however, the correlations was significant for the levels of $\mathrm{Ca}$ and $\operatorname{Ig}(P<0,10)$ and for $S(P<0,05)$. The most significant factors influencing the weight of harvested fruits were the weight of the .. sijps $(P<0,01)$ and the planting season $(P<0,01)$. 
82.

9. IITSRATURA - CITADA

BRASII. Fundação Instituto Brásileiro de Geograria e Estam tística, 1979. Anuário Istatístico do Brasil, . V. 40, 853 p.

AIDERSOI, V.I. e R.A. HCIEAIT., 1974. Design of Lxperiments. New York, Harcel Deklker, Jnc., $418 \mathrm{p}$.

BEI-)AVID, S. e T.G. MONTK., 1975. AlIowing for slope and Intercept Changes in Regression Analysis. Itaca, Cor nell University, $22 \mathrm{p}$.

CARDIIAII, I.R., 1966. Io Simpósio de Abacaxj. IPPACO, Se te Ig:oas, IIG, $30 \mathrm{p}$.

CAIDIIALI, I.R., 1966 a. Espaçanentos de Abacaxi - Compgração de Regiões Frodutoras. In: Seminário da Cultura do A bacaxi, IPAACO, Sete Iagoas, IIG, 2 p. 
CARIJIIIIII, I.R., 1969. Influëncia do Esquema de Plantio e da População de Plantas sobre o Rendimento lo Abacari Ana nas comosus (I.) Merr. Viçosa, U. T.V. 25 p. (Iese de iiestrado).

CARDIIALI, I.R. e J.SIIVA, 1964. Espaçarentos Itilizados na Cultura do Abacaxi em Lagoa Santa, $j_{1}$. In: Seninário da Cultura do Abacaxi, Sete Iagoas, H.G., $4 \mathrm{p}$.

CHEN, V., 1976. Comparing Treatment Means: a Compendium. Hortscience, II (4): 348-357.

COIIIIS, J.I., 1968. The Pineapole, Boteny, CuItivation and Utilization. Iondon, Ieonard Hilleg $295 \mathrm{p}$.

Cosile, O.A., 1979. O Ponto de Colheita do Fruto do Aranszi $z \in$ iro (Ananas comosus ( $I_{0}$ ) Herri:., Cultivar 'Smooti CaI enne'. Piracicaba, ESAIR/USP, 103 p. (Tese de Mestrado).

DULI, G.G., 1971. The Pineapple: General. In: HUIIE, A. C., ed. The Biochemistry of Iruits and Their Products. Iondon, Academic Press, V.2, p. 30;-331.

FAO, 1980. Pineapple. lionthly Bulletin of Statistics: Ro me, $3(5): 17$. 


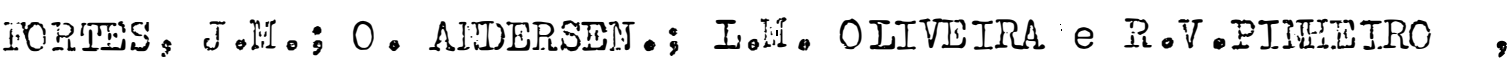
1971. Influência do Tamanho da iluda de Abacaxizeiro, Ananas comosus, (I.) Merr. sobre o Túmero e sobre o Peso Hédjo dos Frutos. Rev. Ceres, Universidade Federal de Viçosa, ijG, 18

GAIIJARD, J.P., 1969. Influence de la late de Plantation et du Poids des Rejets sur Ia Croissance des Ananas au Came ron. Fruits, Paris, 24(2): 75-87.

GIACOIIEIII, I.J., 1972. Estudos sobre o Compoxtamento do Abacaxizeiro (Ananas comosus (I.) Merr., Cultivar 'Cayen ne', na Região de Bebedouro. Piracicaba, ESAIQ/USP, 37 p. (Tese de Doutorado).

GIACOHELIJ, E.J., 1977. Cüss de Ispecialização ein BruticuI tyra: Apontamentos das Ailas de Abacaxicultura. Recife, Cunvênio SUDENE/UNRPE, 106 p.

GIACOIIIII, I.J.; C.PY e P. IOSSOIS, 1979. Istudo sobre 息 poca de Produção para o $\Lambda$ bacaxizeiro 'Cayenne', no Pla nalto PEulista. Anais do V Congresso Brasileiro de Fru ticultura. Pelotas, 2: 4490.511.

GODFREY SAIT-AGGRY, $\%$, 1970. Foliar Analysis as Guide to IISK I Iutrition of Pireapple in the Forest Zone of Chana. Tiusp.Aríc., Great Britain, 6(4):327-333. 
GOVING, D.P., 196I. Experinents on the Photoperiodic ReS ponse in Pineapple. Amer.J.Bot., U.S.A., 48:I6-2I.

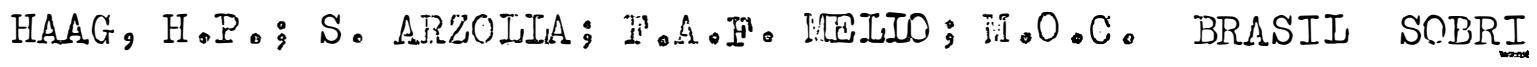
INFO; تAR. OLIVIIRA e E. IIAIAVOIIA, 1963. Estudos sobre a Alimentação ilineral do Abacaxi (Ananas sativus) Sch。 Anais da Escola Superior de Agricultura "Iujz de Queiroz", Piracicaba, SP, 30:33-40。

HAEHDIER, I. e C.PY。, 1971. I'Industrialisation de I'Anonas Aspects et Problemes. Organization des Nations tnies pour le Develo prent Industriel. IIAC, PARIS, $98 \mathrm{p}$.

HICIS, C.R., 1973. Fundamenta I Concepts in the Design of Ixperiments。 U.S.A., HoIt, Rinerart and Winston, Inc., 349 p.

HUET, R., I958. La Composition Chimique de I'Ananas Pruits, Paris, 13(5):183- 197 .

HWAIG, YoJ., 1958. A Comparative Experiment of Fall Plan ting and Spring Planting of Pinespples. J.Agric.Ass... China, 23: 5]-57。

IRFA, 1977. Etudes sur la Croissance et le Developpement de la Plante. In Phase de Frutirication. Frujts, Paris,32 $(7-3): 4.74-4.75$ 
86.

IUCHI, V॰R。, 1973. Efeito do S'ulfato de Amônio, Superfos fato Simples e Sulfato de Yotássio sobre Algurnas caracte rísticas da Planta e Qualidade do Pruto do Abacaxizeiro, Ananas comosus $\left(I_{0}\right)$ inerr., Variedade 'Smooth Cayenne'。 Universidade Federal de Viçosa, NG, 61 p. (Tese de itestrado).

JANICK, J., 1966. A Ciếncia da Florticultura. 沉inistéxio da Agricultura e USAID. Ia ed. em Portuguës, 485 p.

JOHISTON, J., 1963. Econometric Methods. New York, McGraw HiIl. Inc., $300 \mathrm{p}$.

KAITAPATHY, Ko, 1958. Ieaf Analysis in Relation to Yield and

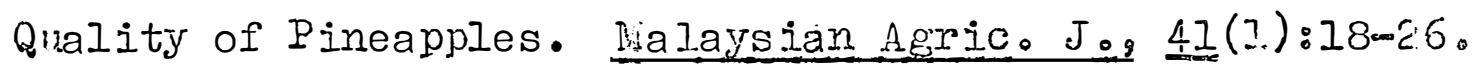

PIICHELI, A.R., 1962. Plant Develooment and Yield in Pine apple as Affected by Size and Type of Planting Material and Time of Planting and Forcing. Qd. J.Agric. Sci.,Aus trália, 19:453-466.

VITCHEII, A.R. e M.T. NICHOLSON, 1965. Pineapple Growth and Yield as Influenced by Urea Spray Schedules and $P_{Q}$ tassium Ievels at Three Plant Spacings. Qd.J.Agric. Sci., Austrália, 22: 409-117. 
IHOMTITEGRO, H.W.S., 1964. A Haturação do Abacaxi. Ana is da Escola Superior de Agricultura "Iuiz de Queiroz", Piraci caba, SP, 2I: 80- 92 .

PAI, KoY., 1957. Research on the Three Essential Fertilizers of Pineapples. J.Agric. 4ss. China, 19:11-29.

PIHTHTAL GOHES, F。, 1976. Curso de Estatística Experimental. 6 ed., São Paulo, Iivraria Nobel, 430 p.

PY, C., 1964. sperçu sur le Cycle de L'ananas en Martinique. Frujts., Paris, 19(3): 133-139.

PY, C., 1970. Les lileilleures Dates de Plantation des Ana-w nas en Tartinique en Vue de la Production pour I'Usine. iruits, Paris, 25(3): $199-203$.

PY, C., 1973. L'Ananas, Qualité et Cout en Relation avec le irilieu. Fruits., Paris, 28: 127-131.

PY, C。, H.A. IISSEAU; B。OURY; F. AHIIADA, 1957. Ia Culture de I'ananas en Guinee. Paris, IFAC, 331 p.

PY, C。 e H.A. IISSEAU, 1965. L'Ananas. Paris, Maisonneuve \& Larose, $298 \mathrm{p}$.

PY, Co; P. INSSOIS e IT. KARAIIIAR, 1968. Contribution à I' Śtude du Cycle de I'Ananas. Iruita.g Paris, 23(3):403.0 4.13. 
RTYMEARDT, J.P.K॰ e E。R.DAIIDORF, 1968. Planting Naterial for the Cayenne Pineapple. Mrng. S. Arica, 44(2):24-25.

SAIUUIS, G॰; P. IAIDRAU Jr。 e R。 OIIVENCIA, 1955. Response of Pineapple to Applications of Fertilizers. J.Agric. Univ., Porto Rico, 39, (I): I-II.

SGARBIERI, V.C., 1966. Composição do Abacaxi. Boletim do Centro Tropical de Pesquisas e Tecrolocia de Alimentos. Campinas, (7): 39-50.

SImÃO, S., 1971. Manual de Frutjcultura. Sao Paulo, Edito ra Agronômica Ceres, $530 \mathrm{p}$.

SIMGIETON, W。I。 e W.A.GORTNER, 1965. Chemical and Physi cal Development of the Pineapple Fruit II. Carbchrate and Acid Constituents. Journai of Food Science. hicago, 30: $19-23$.

SOUZA, Jr., A.J., 1972. Industrialização do Abacaxi. Bole tim do Instituto de Tecnologia de Alimentos. Campinas, 30: $: 1-34$.

SU, IN.R。, 1956. Influence of Soil Fertility and Plant Nu trition on the Yield and Properties of Pineapple Fruits. J. Agric. Ass. China, 13: 570065. 
SU, H.Ro, 1957. Spacing and Fertilizer Ievel as Two Dominant Factors in the Productions of Pineapples. J.Agrigo Ass. China, 17: 42-67.

TAY, T.H०; KEE, P.C. e VED, Y॰C., 1969. The Nutritional Re quirements of Pineapples (Ananas comosus. (I.) Merr. Var. Singapore Spanish) on Peat Soil in Halaya. II. Ieaf Anàlysis in Relation to Yield Sugar and Acid Contents of the Fruits. Malaysian Agric..Jo, 47(2): 175-186.

TAY, ToH. e Y。C。VEE, 1976. Comparative Study on the Ef fects of Different Types and Sizes of Planting liaterials on Pineapple Yield and Quality Malaysian Agric.J. $20(4): 502-506$.

TaISSOH, II., 1972. Etude $0 x$ la Floraison ivaturelle de I'Ananas en Cote D'Ivoi:e. Fruits., Paris, 27(10):699 704 .

TRETO, E。; A. GOITAIES e JorT. GOHEZ, 1974. Ŕtude de Différentes densités de Plantation Chez la Varieté D'Anaras Ispanolla Roja (Red spanish) à Cuba. Pruits., Paris,29 (4) : 279-284.

VASCOICYILOS, D.H., 1952. Adubação do Abacaxizeiro. Boletiri da Secretaria da Asricultura Ind. Com. Pernambuco. Recj.fe, $207 \mathrm{p}$. 
WANG, Ho e S.P. CHANG, 1959. An Experiment on Close Planting of Pineapple II. Taiwan Aric. Res. Inst. $8 \mathrm{p}$ 。

WAITG, W.K. e K. H. KWONG, 1966. Yield of Pineapple as Affected by Size of Slips for Fall Planting. J.Agxic. Ass. China, 55: 50-55.

WEE, Y.C., 1969. Planting Density Trials With (Ananas cono sus (Io) Herr.Var. Singapore Spanish). Malaysian Arric. J., $47(2):$ 164-174。

YOSTIFARA, H。 e Y.J.HWANG, 1957. A Study in the Relation Between Planting Distance and Yield of Pineapple. I. Agric. Ass. Ching, 18: 59-66. 
APENDICE 


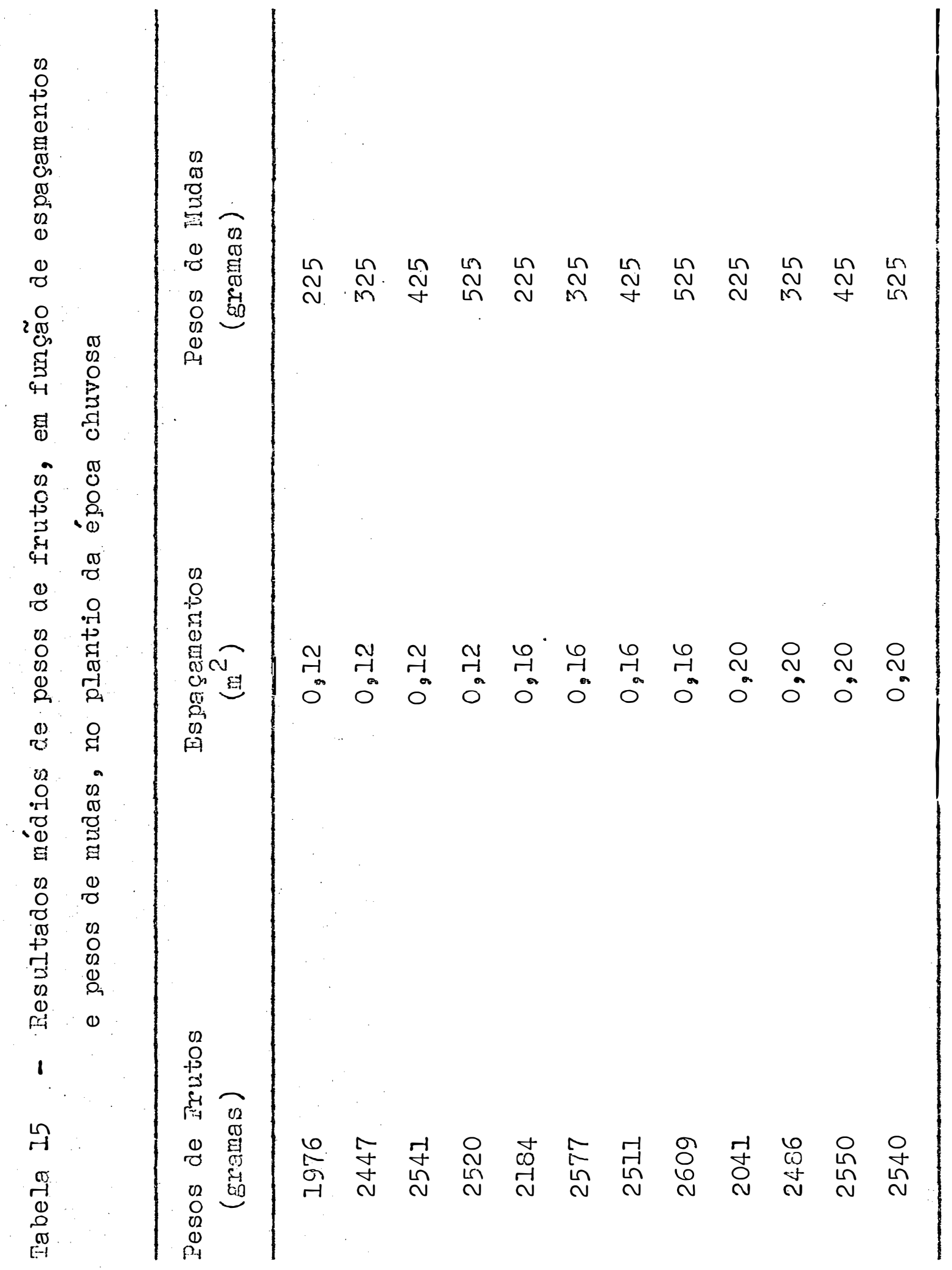



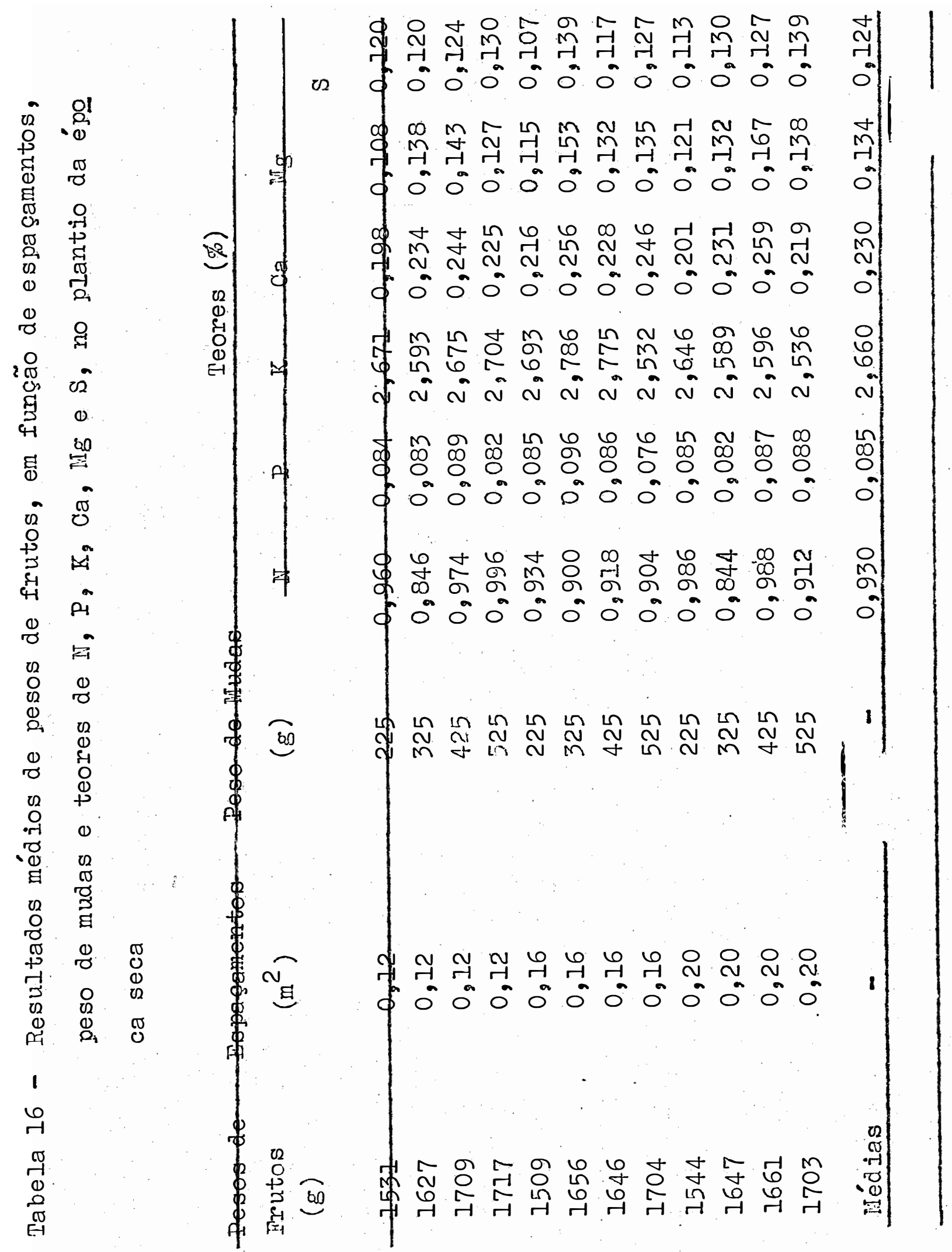